\title{
Hybrid (Dynamical-Statistical) Models to Improve Seasonal Drought Prediction: Application to Regional Meteorological Droughts in China
}

\section{Zhiyong Wu ( $\sim$ zywu@hhu.edu.cn )}

Hohai University College of Hydrology and Water Resources https://orcid.org/0000-0001-7186-3776 Hao Yin

Hohai University College of Hydrology and Water Resources

Hai He

Hohai University College of Hydrology and Water Resources

Yuan Li

Hohai University College of Hydrology and Water Resources

\section{Research Article}

Keywords: Seasonal drought prediction, Hybrid models, Machine learning, China

Posted Date: February 23rd, 2021

DOI: https://doi.org/10.21203/rs.3.rs-198381/v1

License: (c) (i) This work is licensed under a Creative Commons Attribution 4.0 International License.

Read Full License 


\section{Hybrid (dynamical-statistical) models to improve seasonal drought 2 prediction: application to regional meteorological droughts in China}

3 Zhiyong $\mathrm{Wu}^{1,2} \cdot \mathrm{Hao} \mathrm{Yin}^{1} \cdot \mathrm{Hai} \mathrm{He}^{1} \cdot$ Yuan $\mathrm{Li}^{1}$

$4 \quad{ }^{1}$ College of Hydrology and Water Resources, Hohai University, Nanjing 210098, China

$5 \quad{ }^{2}$ Yangtze Institute for Conservation and Development, Hohai University, Nanjing 210098, China

6 Correspondence to: Zhiyong Wu (wzyhhu@gmail.com)

\section{Abstract}

8 Accurate drought prediction is important for drought resistance and water resources management. However, the seasonal 9 drought prediction is of low accuracy for both dynamical and statistical models. In this study, we combined dynamical models 10 and machine learning to construct hybrid (dynamical-statistical) models. We used the random forest approach to identify 11 representative regions based on geopotential height, sea-level pressure, and 2-m temperature. The least absolute shrinkage and 12 selection operator (Lasso and an artificial neural network (ANN) were used to construct the statistical models, with atmospheric 13 variables as predictors and 3-month Standardized Precipitation Index (SPI3) as the predictand. The atmospheric variables 14 forecasted by the European Centre for Medium-Range Weather Forecasts (ECMWF) SEAS5 model were processed as 15 predictors to force the statistical models. The resulting hybrid models, constructed using dynamical models and machine 16 learning, were named as dynamic-Lasso ('D-Lasso') and dynamic-ANN ('D-ANN') separately. The results suggested that 17 prediction skills were improved by the hybrid models; compared to the best available dynamical model (UK Met Office), D18 ANN extends the forecast horizons by 6, 21, and 4 days in northern, eastern, and southern China, respectively. In spring and 19 summer, the correlation skills were also improved. The effective prediction of the atmospheric anomalies over the eastern and 20 southern Tibetan Plateau and the Northwest Pacific region was identified as the main contributor to successful seasonal drought 21 prediction. Overall, the hybrid models were able to predict drought processes effectively, and D-ANN outperformed the D22 Lasso in drought onset and persistence phases.

23 Key words Seasonal drought prediction $\cdot$ Hybrid models $\cdot$ Machine learning $\cdot$ China

\section{Introduction}

25 Droughts are natural disasters that occur under all climate regimes (Liu et al. 2016). Global chronically drought-prone areas have increased significantly, from 16.19\% between 1902 and 1949 to $41.09 \%$ between 1950 and 2008 (Wang et al. 2014). Globally, an estimated 55 million people are affected by droughts every year, and as many as 700 million people are at risk of 
being displaced as a result of drought by 2030 (World Health Organization 2019). According to the Food and Agriculture Organization (FAO) of the United States, developing countries suffered losses of \$29 billion in agriculture due to droughts between 2005 and 2015 (Conforti et al. 2018). Therefore, effective drought prediction is important to improve drought resistance and water resources management, and reduce drought losses.

With the increase of our understanding of the climate system and computational capabilities, predicting droughts using general circulation models (GCMs) has become a fundamental approach (Hao et al. 2018). Seasonal drought indices, such as the Standardized Precipitation Index (SPI) and the Standardized Precipitation Evapotranspiration Index (SPEI), can be calculated from GCM precipitation and temperature outputs (Lang et al. 2020; Ma et al. 2015; Ujeneza and Abiodun 2015). The advantage of GCMs is that they are based on physical principles and can capture the nonlinear changes in the ocean, atmosphere, and on land. In recent years, significant advances have been made in drought prediction, with the widespread use of post-processing and multi-model ensembles (Li et al. 2020; Mo and Lyon 2015). Nevertheless, GCMs are limited by chaotic properties, initial value errors, and model biases, which lead to uncertainties in the forecasted precipitation with a lead time of more than two weeks (Li et al. 2017; Merryfield et al. 2020). Statistical methods usually first identify a range of predictors from historical hydroclimatic observations (reanalysis) which are then input into statistical models to predict drought. Statistical methods are less computationally demanding and usually provide a baseline level of skill (Kirtman et al. 2013). However, unclear physical mechanisms and unstable statistical relationships in climate change are always the problems of statistical methods (Hao et al. 2018). To combine the advantages of dynamical and statistical models, many researchers have attempted to construct hybrid (dynamical-statistical) models.

Hybrid models mainly involve two steps, first, calibration to correct the bias (and ensemble spread) of GCMs forecasts and, second, merging forecasts from multiple sources (Madadgar et al. 2016; Ribeiro and Pires 2016; Yan et al. 2017). Previous efforts have focused on combining forecasts from multiple dynamical and statistical models, which has achieved excellent results (Hao et al. 2016; Madadgar et al. 2016; Wang et al. 2012). Nevertheless, some variables, such as geopotential height and temperature, yield higher skill scores with long lead times and are often used to analyze atmospheric circulation anomalies during droughts but are rarely used for prediction. For seasonal drought, large-scale circulation is an important mechanism, and the role of atmospheric anomalies varies between droughts (Lhotka et al. 2020; Li et al. 2018b; Okumura et al. 2017; Zhuang et al. 2020). Thus, some studies have aimed to extract information from atmospheric circulation patterns to predict drought events. For example, Costa-Cabral et al. (2016) were able to project meteorological drought in California using the North Pacific High (NPC) sea-level pressure anomaly; in northeastern Europe, more than $65 \%$ of drought events were detected one month in advance by Lavaysse et al. (2018); and Richardson et al. (2020) explored the potential benefits of using weather pattern predictions to improve sub-seasonal forecasts of meteorological drought. In these studies, the selection of an appropriate method to obtain key information from atmospheric variables was critical.

With the explosive growth of observation (and reanalysis) data and the considerable increases in computing capabilities, climate prediction with machine learning (ML) has become an active area of research (Reichstein et al. 2019). The most significant advantage of ML is its ability to mine information from 'big data' for future prediction. In the past few years, ML 
62 has helped improve climate predictions significantly as well as assist in interpreting the underlying mechanisms (Pan et al.

63 2020; Yoo-Geun et al. 2019), and this approach has also been used to improve drought prediction (Agana and Homaifar 2017;

64 Khan et al. 2020; Rezaeianzadeh and Tabari 2012; Zhang et al. 2019). However, drought mechanisms vary between different

65 regions and across temporal-spatial scales, meaning that further research is needed to determine whether ML is effective for

66 seasonal drought prediction.

67 China has long been affected by drought due to its geographical location and climatic regime (Ayantobo et al. 2017), and in

68 recent years, extreme droughts have become increasingly frequent and severe in eastern and southern China (Chen et al. 2018;

69 Jin et al. 2013; Ma et al. 2020). For example, the great drought in southwestern China from September 2009 to March 2010

70 affected more than 69 million people and 6.6 million hectares of crops, with economic losses of more than 40 billion yuan

71 (China Meteorological Administration 2011). In 2013, drought in southern China affected more than 80 million people and

72 damaged 7.9 million hectares of crops (China Meteorological Administration 2014). While progress has been made in drought

73 prediction in China using dynamical models, statistical methods, and hybrid models (Xu et al. 2018a; Xu et al. 2018b; Zhang

74 et al. 2019; Zhu et al. 2020), there have been few attempts to employ atmospheric circulation datasets. Therefore, the

75 applicability of ML for seasonal drought prediction in different regions of China remains unknown.

76 In this study, we combine dynamical models and ML to construct hybrid models. We use a random forest (RF) approach to 77 identify typical regions from atmospheric circulation variables. The least absolute shrinkage and selection operator (Lasso) 78 and an artificial neural network (ANN) are used to extract statistical relationships between atmospheric variables in 79 representative regions and meteorological drought. The atmospheric variables forecasted by the dynamical models are then 80 processed to generate drought-prediction models. The remainder of this paper is structured as follows: Section 2 introduces 81 the study area and data; the ML models and predictor construction methods are described in Sect. 3; Section 4 presents the 82 prediction results; we will discuss the study limitations and directions for future work in Sect. 5; and the conclusions are 83 presented in Sect. 6.

\section{Study areas and data}

\section{$85 \quad 2.1$ Study areas}

86 Three of the nine drought regions of China (Fig. 1), namely Northern China (North), Eastern China (East), and Southern China

87 (South), were selected as the study regions, covering approximately $0.69,0.91$, and 0.37 million $\mathrm{km}^{2}$, respectively. The East

88 Asian Monsoon climate greatly influences these regions, and precipitation shows large inter- and intra-annual variability (Cai 89 et al. 2017; Liu and Huang 2019; Zhang 2015). 


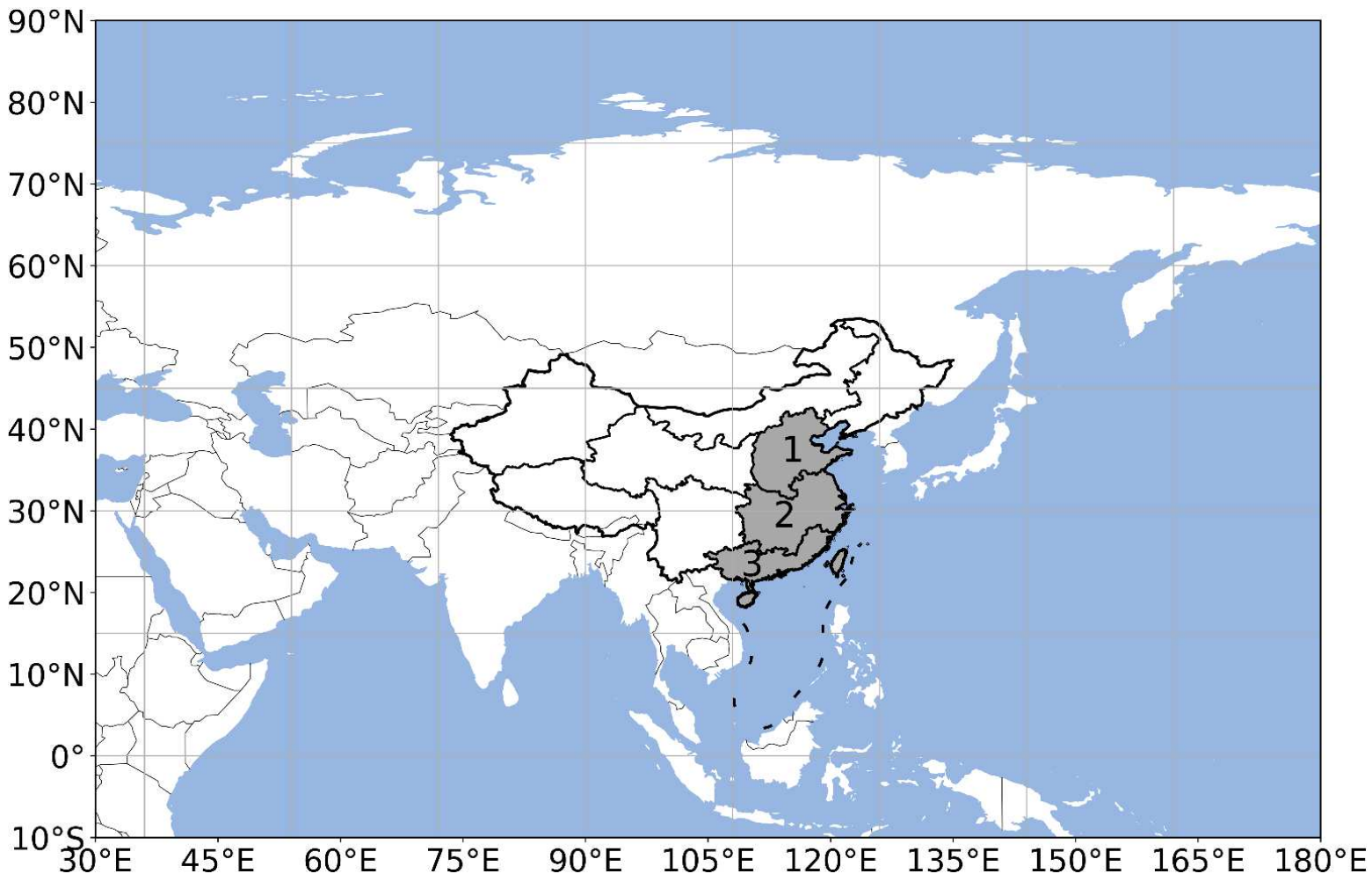

Fig. 1 The location of the drought regions of China and the coverage of atmospheric variables $\left(30^{\circ}-180^{\circ} \mathrm{E}, 10^{\circ} \mathrm{S}-90^{\circ} \mathrm{N}\right)$. $\mathrm{The}$ gray shaded areas are the study regions. 1-3 represent Northern, Eastern, and Southern China, respectively

\subsection{Data}

\subsubsection{Observations}

Observed daily precipitation amounts from the Climate Data Centre (CDC) of the National Meteorological Information Centre, China Meteorological Administration (CMA), were used, providing $0.5^{\circ} \times 0.5^{\circ}$ gridded data for the period 1979-2019 (http://data.cma.cn/data/detail/dataCode/SURF_CLI_CHN_PRE_DAY_GRID_0.5.html). These data were initially used to calculate area-averaged precipitation over the three selected regions.

The following atmospheric circulation information was obtained from the European Centre for Medium-Range Weather Forecasts (ECMWF) ERA5 reanalysis dataset (https://www.ecmwf.int/en/forecasts/datasets/reanalysis-datasets/era5) at a $2^{\circ} \times$ $2^{\circ}$ resolution for the area $30-180^{\circ} \mathrm{E}, 10^{\circ} \mathrm{S}-90^{\circ} \mathrm{N}$ : geopotential heights at 200,500 , and $850 \mathrm{hPa}(\mathrm{GH} 200, \mathrm{GH} 500$, and GH850); 2-m temperature (T2M); and sea-level pressure (SLP).

\subsubsection{GCM hindcast data}

We focused on seasonal drought prediction for the next 90 days, corresponding to the 'seasonal scale' discussed throughout the paper. For this, data for the atmospheric variables (in 90-day blocks) were downloaded from the ECMWF SEAS5 hindcast 
dataset for the period 1993-2016 (https://cds.climate.copernicus.eu/cdsapp\#!/dataset/seasonal-original-single-levels), including GH200, GH500, GH850, T2M, and SLP. For comparison, we selected hindcast data from the ECMWF, UK Met

108 Office (UKMO), and Météo France (https://cds.climate.copernicus.eu/cdsapp\#!/dataset/seasonal-original-single-levels)

109 hindcast precipitation (Table 1).

110 Table 1 Data used in this study

\begin{tabular}{ccccc}
\hline Data type & Variable name & $\begin{array}{c}\text { Pressure level } \\
(\mathrm{hPa})\end{array}$ & Abbreviation & Data source \\
\hline $\begin{array}{c}\text { Atmospheric } \\
\text { variables }\end{array}$ & $\begin{array}{c}\text { 2-m temperature } \\
\text { Sea-level pressure } \\
\text { Geopotential } \\
\text { height }\end{array}$ & $\begin{array}{c}\text { surface } \\
\text { surface }\end{array}$ & $\begin{array}{c}\text { T2M } \\
\text { SLP }\end{array}$ & Reanalysis: ERA5 reanalysis \\
Precipitation & Total precipitation & surface & GH200/GH500/GH850 & Hindcast: ECMWF SEAS5 \\
\hline
\end{tabular}

1113 Methodology

\section{3.1 Daily-updated Standardized Precipitation Index}

113 As a seasonal drought index, the SPI3 was calculated for the three study regions using area-averaged precipitation data.

114 Traditionally, the SPI3 varies on a monthly scale, reflecting cumulative precipitation over the past three months; however, a

115 monthly timescale does not well reflect the evolution of drought onset, persistence, and relief, presenting limitations for

116 meeting the requirements for real-time monitoring and prediction for effective management. Therefore, we followed the World

117 Meteorological Organization (WMO) recommendation to adjust the sliding time window of the SPI3 to 90 days (Svoboda et 118 al. 2012). Thus, we obtained information on the daily variation of meteorological droughts while the mathematical treatment 119 remained unchanged. Full calculation details are given by Liu et al. (2018).

\section{3.2 Predictor construction}

121 Hart and Grumm (2001) first used standardized anomalies to delineate weather-scale events, and this approach has been used 122 in an increasing number of studies to identify atmospheric and oceanic anomalies (Duan et al. 2014; Liu et al. 2018; Liu et al.

123 2017). Here, we calculated 90-day standardized anomalies (SA90) using the following equation:

$124 \mathrm{SA} 90=\frac{X_{90}-\mu_{90}}{\sigma_{90}}$,

125 where $X_{90}$ represents the mean values of atmospheric variables over the past 90 days; and $\mu_{90}$ and $\sigma_{90}$ are the mean and 126 standard deviation of the 90-day period, respectively. The climatic background period selected for this study was 1981-2010. 127 For example, $X_{90}$ for 1 April 2000 represented the 90-day average for the period from 3 January 2000 to 1 April 2000; and $\mu_{90}$ 128 and $\sigma_{90}$ are the 90-day average and standard deviation for the period from 3 January 1981 to 1 April 2010. The ERA5 reanalysis 

the considered atmospheric variables (i.e. SA90 ${ }_{\mathrm{GH} 200}, \mathrm{SA} 90_{\mathrm{GH} 500}, \mathrm{SA} 90_{\mathrm{GH} 850}, \mathrm{SA} 90_{\mathrm{T} 2 \mathrm{M}}$, and $\mathrm{SA} 90_{\mathrm{SLP}}$ ).

\section{1}

132

133

134

135

136

137

138

139

140

141

\section{2}

143

144

145

\subsection{Machine learning models}

\subsubsection{Construction of ML models}

We constructed ML models for each of the three drought regions using 32 years of data from 1980 to 2011 for training and 8 years of data from 2012 to 2019 for validation. The models adopted the daily five-layer SA90 dataset as the predictor and the SPI3 as the predictand. The model structure is shown in Fig. 2. First, we flattened the five-layer SA90 into a column of $5 * 51 * 61$ data points (the input neurons), extracted typical data through the RF, and then produced the output SPI3 data by forcing the Lasso and ANN. The ML models (RF, Lasso, and ANN) are described in detail in Supplement 1-3.
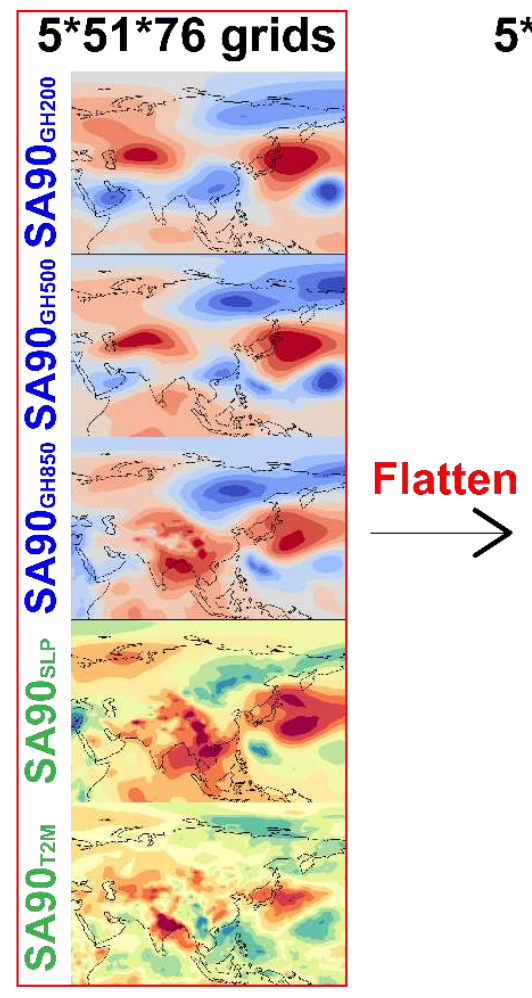

$5 * 51 * 76$ units

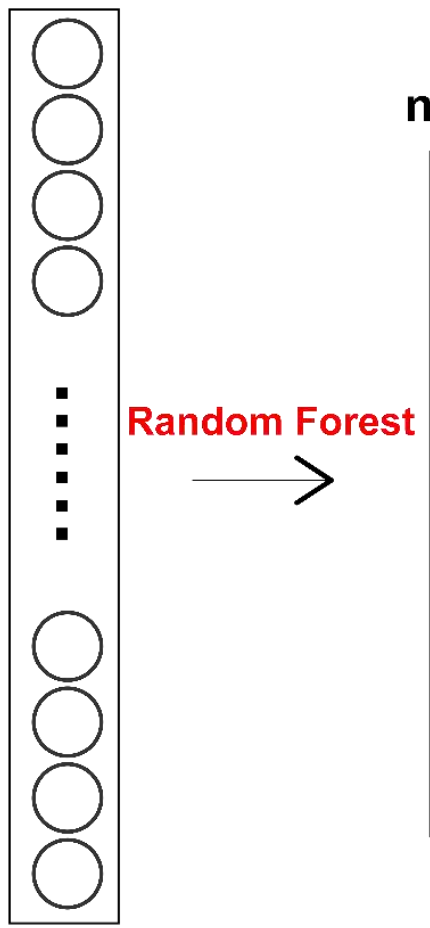

\section{n units}

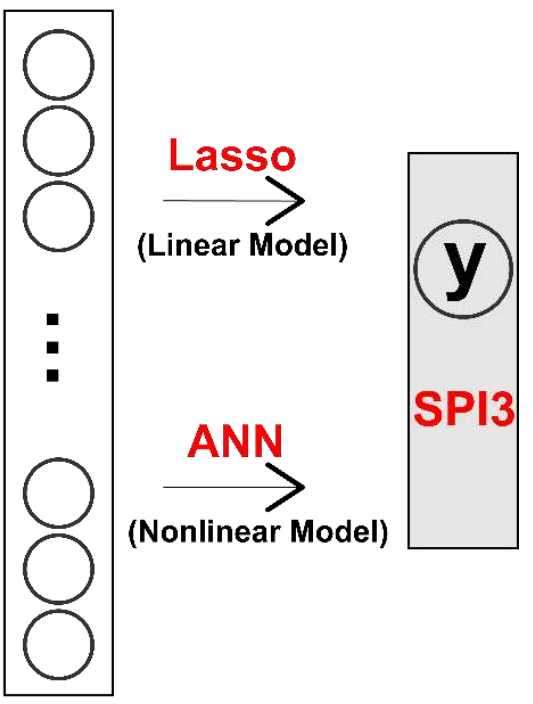

Fig. 2 ML model structure, where ANN contains a single layer and 16 nodes. $\mathrm{SA90}_{\mathrm{GH} 200}, \mathrm{SA90}_{\mathrm{GH} 500}, \mathrm{SA90}_{\mathrm{GH} 850}, \mathrm{SA90}_{\mathrm{T} 2 \mathrm{M}}$, and SA90 SLP are the 90-day standardized anomalies of GH200, GH500, GH850, SLP and T2M, respectively. Lasso is a linear model, while ANN is linear

\subsubsection{Calculation of the prospective Nth-day SPI3}

The ML models constructed in Sect. 3.3.1 incorporate the contemporaneous statistical relationships between the predictors and the SPI3 and, therefore cannot predict the future. During the training and validation periods, the models were forced with ERA5 data. For prediction, we first calculated SA90 using ERA5 reanalysis data for the past (90-1-N) days, ECMWF outputs 
146 for the prospective $\mathrm{N}$ days, and then forced the ML models to predict the Nth-day SPI3, as shown in Fig. 3. Therefore, the

147 drought prediction models we construct were hybrid (dynamical-statistical) models, which we name dynamic-Lasso (' $\mathrm{D}$ -

148 Lasso') and dynamic-ANN ('D-ANN'), respectively.

149

$158 \quad$ RMSE $=\sqrt{\frac{\sum_{i=1}^{n}\left(y_{i}-x_{i}\right)^{2}}{n}}$,

where $x_{i}$ represents the observed value, $y_{i}$ represents the predictand, and $n$ represents the sample size.

160 The correlation coefficient (Corr) was used as the performance evaluation function for ML to measure the correlation between 161 the model output and the expected values:

$162 \operatorname{Corr}=1-\frac{\sum_{i=1}^{n}\left(x_{i}-\bar{x}\right)\left(y_{i}-\bar{y}\right)}{\sqrt{\sum_{i=1}^{n}\left(x_{i}-\bar{x}\right)^{2}} \sqrt{\sum_{i=1}^{n}\left(y_{i}-\bar{y}\right)^{2}}}$,

163 where $x_{i}$ is the observed value, $y_{i}$ is the predictand, $\bar{x}=\frac{1}{n} \sum_{i=1}^{n} x_{i}$ (the sample mean), and analogously for $\bar{y}$; and $n$ represents 164 the sample size.

Fig. 3 Schematic representation of the calculation process for the prospective Nth-day SPI3

\subsubsection{GCM hindcast precipitation}

The SPI3 calculated from the ECMWF, UKMO, and Météo France hindcast precipitation datasets were compared with the hybrid models. For prediction, we use observed precipitation for the past (90-1-N) days, GCM outputs for the prospective N days, and then calculated the Nth-day SPI3.

\subsubsection{Evaluation metrics}

Root-mean-square error (RMSE) was adopted as the loss function to describe the error between the model output and the observed data, and for the inverse calculation of the network residuals, as follows:

\section{Calculate SA90}

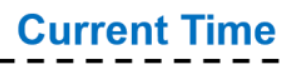

\section{SPI3}

D-ANN (The prospective $\mathrm{N}^{\text {th }}$ day) 


\subsection{Identification of droughts}

167 A drought event is defined as a number of consecutive days (> 60 days) with daily updated SPI3 values of $<-0.5$. Based on 168 this approach, the droughts identified between 1979 and 2019 in the study regions are shown in Table 2.

169 Table 2 Drought events identified in the three study regions between 1979 and 2019

\begin{tabular}{cccc}
\hline & & Regions & \\
\hline & North & East & South \\
& & $1981 / 06 / 18-1981 / 10 / 06$ & $1984 / 01 / 11-1984 / 04 / 17$ \\
& & $1984 / 01 / 12-1984 / 04 / 07$ & $1985 / 05 / 20-1985 / 09 / 05$ \\
& $1981 / 05 / 03-1981 / 08 / 16$ & $1985 / 05 / 31-1985 / 09 / 23$ & $1986 / 09 / 10-1986 / 11 / 17$ \\
& $1984 / 01 / 16-1984 / 05 / 23$ & $1986 / 02 / 20-1986 / 06 / 22$ & $1988 / 06 / 07-1988 / 08 / 31$ \\
& $1986 / 03 / 23-1986 / 08 / 09$ & $1986 / 08 / 18-1986 / 11 / 14$ & $1989 / 07 / 06-1990 / 01 / 10$ \\
1989/09/03-1989/11/11 & $1988 / 06 / 23-1988 / 09 / 04$ & $1991 / 04 / 03-1991 / 08 / 15$ \\
Dates & $1991 / 09 / 09-1992 / 01 / 25$ & $1992 / 07 / 26-1993 / 01 / 13$ & $1992 / 09 / 12-1993 / 01 / 13$ \\
& $1992 / 06 / 10-1992 / 09 / 22$ & $1995 / 12 / 28-1996 / 03 / 25$ & $1996 / 01 / 04-1996 / 03 / 27$ \\
& $1995 / 03 / 07-1995 / 06 / 19$ & $1998 / 10 / 26-1999 / 04 / 23$ & $1996 / 11 / 14-1997 / 01 / 23$ \\
$1995 / 12 / 31-1996 / 05 / 02$ & $2000 / 04 / 07-2000 / 06 / 22$ & $1998 / 09 / 21-1998 / 12 / 01$ \\
& $1997 / 06 / 11-1997 / 11 / 14$ & $2001 / 04 / 05-2001 / 06 / 19$ & $1999 / 01 / 25-1999 / 05 / 25$ \\
$1998 / 11 / 02-1999 / 04 / 10$ & $2001 / 06 / 21-2001 / 08 / 30$ & $2002 / 03 / 09-2002 / 06 / 17$ \\
& $1999 / 07 / 14-1999 / 10 / 31$ & $2001 / 09 / 01-2001 / 11 / 04$ & $2003 / 03 / 25-2003 / 06 / 13$ \\
& $2000 / 03 / 23-2000 / 06 / 26$ & $2003 / 09 / 25-2003 / 12 / 10$ & $2003 / 07 / 03-2004 / 02 / 04$ \\
& $2001 / 04 / 12-2001 / 08 / 18$ & $2004 / 03 / 07-2004 / 05 / 14$ & $2004 / 05 / 22-2004 / 08 / 03$ \\
& $2002 / 08 / 04-2002 / 12 / 05$ & $2004 / 10 / 11-2005 / 01 / 08$ & $2004 / 10 / 09-2005 / 02 / 05$ \\
$2008 / 12 / 23-2009 / 02 / 24$ & $2007 / 05 / 06-2007 / 07 / 11$ & $2005 / 11 / 12-2006 / 02 / 26$ \\
& $2010 / 12 / 16-2011 / 02 / 27$ & $2007 / 11 / 21-2008 / 01 / 27$ & $2007 / 11 / 19-2008 / 01 / 30$ \\
$2011 / 05 / 26-2011 / 08 / 25$ & $2009 / 09 / 27-2009 / 12 / 02$ & $2009 / 01 / 31-2009 / 04 / 19$ \\
$2013 / 03 / 22-2013 / 05 / 25$ & $2011 / 03 / 07-2011 / 08 / 04$ & $2009 / 10 / 01-2009 / 12 / 01$ \\
$2014 / 07 / 15-2014 / 09 / 27$ & $2013 / 03 / 14-2013 / 05 / 15$ & $2011 / 03 / 11-2011 / 10 / 24$ \\
& $2013 / 07 / 28-2013 / 10 / 09$ & $2012 / 09 / 20-2012 / 11 / 21$ \\
& $2019 / 10 / 10-2019 / 12 / 21$ & $2018 / 04 / 05-2018 / 07 / 06$ \\
\hline
\end{tabular}

\section{$170 \quad 4.2$ Simulated SPI3 in validation periods}

171 According to Sect. 3, we constructed ML models based on data for the period 1980-2011. To test the robustness of the models,

172 we forced the Lasso and ANN models for the period between 2012 and 2019 (Fig. 4). Both of these models' simulations were

173 consistent with the observed SPI3 trends in all three regions, although ANN performed better overall, especially when

174 simulating extreme values. This indicates that the ANN has a better information-extraction capability and better captures

175 nonlinear atmospheric processes. In addition, the models performed much better for the east and south regions than the north study region, which may reflect the differing drought mechanisms in these regions. 

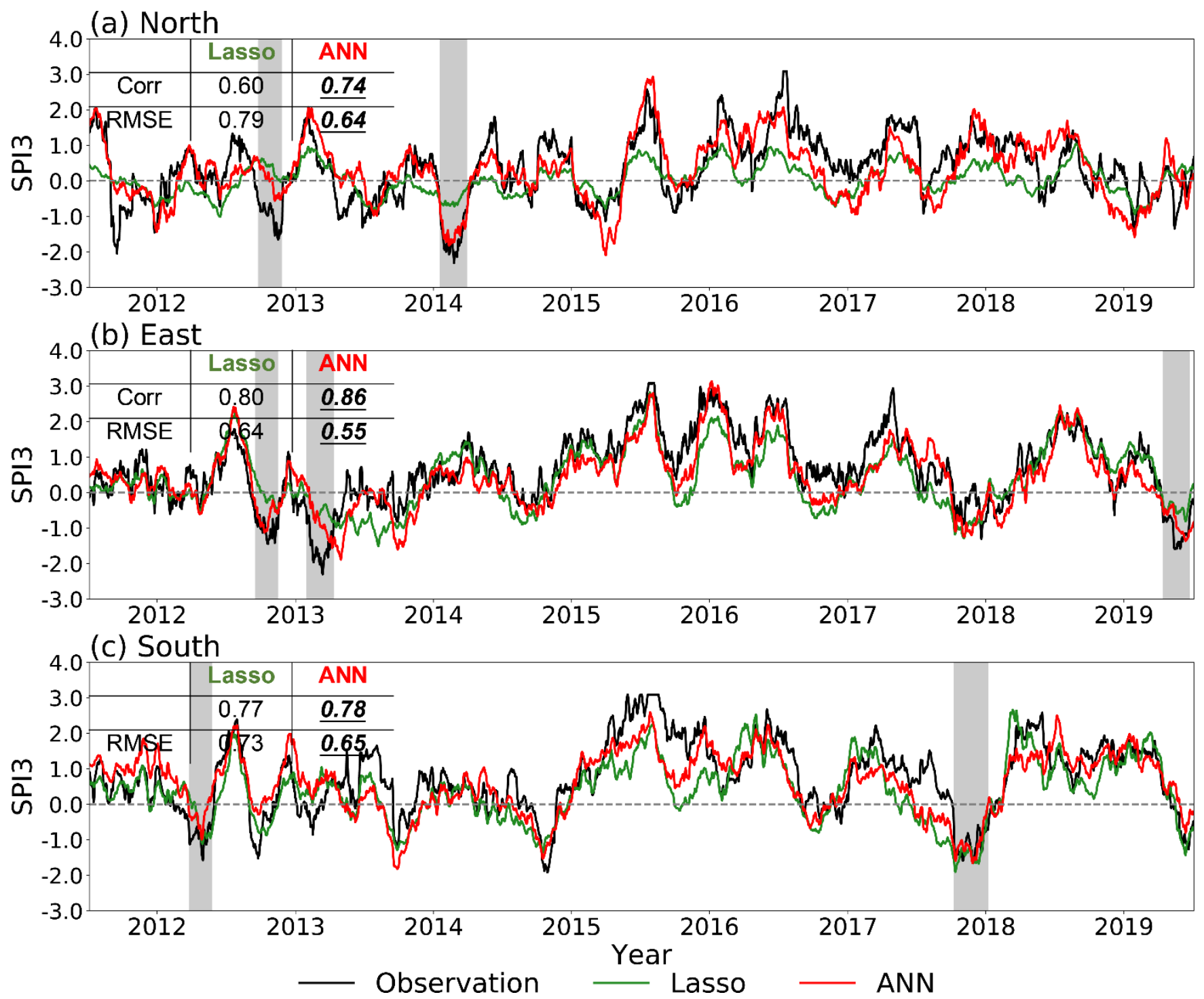

Fig. 4 Temporal trends in the observed and simulated SPI3 during the validation period (1 January 2012 to 31 December 2019 ). The black curve is the observed SPI3, and green and red curves are the Lasso and ANN simulations, respectively. The grey shading shows the identified drought events in Sect. 4.1

\subsection{Seasonal drought prediction}

Between 1993 and 2016, ECMWF hindcasts data for the first day of each month, as do D-Lasso and D-ANN. Therefore, we generated five sets of seasonal drought prediction products (SPI3) based on the Météo France, ECMWF, UKMO, D-Lasso, and D-ANN datasets.

Fig. 5 shows the correlation results of the SPI3 between 1993 and 2016. The strength of the correlations between all five models decreases as the lead time increases. At three weeks or less, the correlation between the ECMWF and UKMO outputs 
is stronger than that of the hybrid models, indicating that dynamic models are more accurate in simulating precipitation with short lead times, which is consistent with other analyses (Lang et al. 2014; Li et al. 2017). However, when the lead time exceeds 20 days, the hybrid models always outperformed the dynamic models; in particular, D-ANN showed the best performance for lead times above 30 days, which indicates that nonlinear hybrid models further improved drought predictions.

191 Data correlations also differed between the study regions. For example, outputs from both the dynamical and hybrid models

192 in the north region had lower correlation skills than the other two models. Among the three dynamical models, the UKMO model was best for seasonal drought prediction. Following Buizza and Leutbecher (2015), we determined the forecast lead times at which the correlation skills of the models were no longer higher than 0.5, defined as the forecast skill horizon. Based on this, D-ANN extended the forecast skill horizon by 6,21 , and 4 days in the north, east, and south regions, respectively, relative to the UKMO model. In particular, the correlation of D-ANN was higher than 0.5 with a 76 -day lead time in the east region, while the correlations of the Météo France, ECMWF, and UKMO data were 0.18, 0.29, and 0.34, respectively.

(a) North
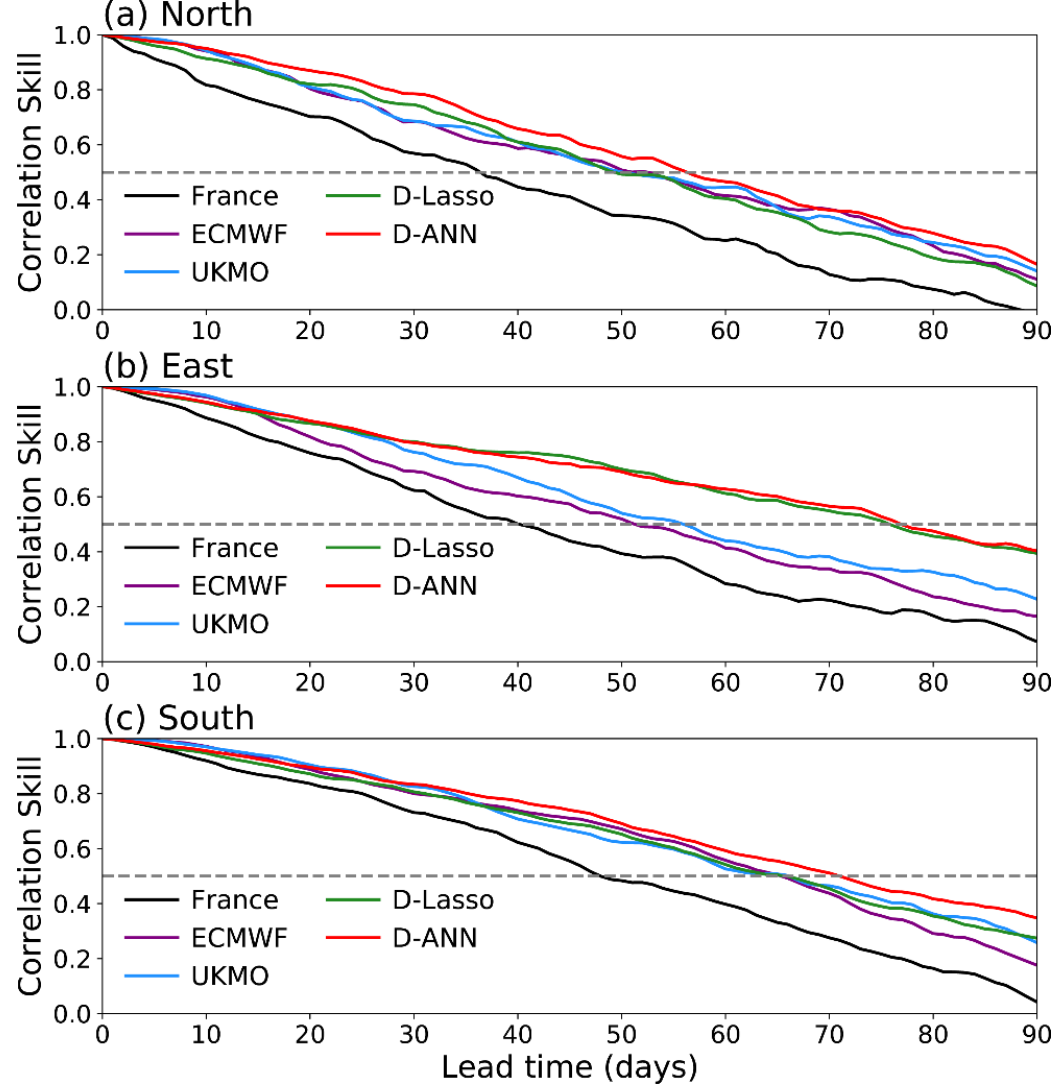

Fig. 5 Correlation skills between five models predicting SPI3 at different lead times. Black, purple, blue, green, and red curves represent Météo France, ECMWF, UKMO, D-Lasso, and D-ANN outputs, respectively. The grey dashed lines indicate a correlation of $\mathbf{0 . 5}$ 


\subsection{Prediction skills across all months}

203 Figure 6 shows the SPI3 correlation skills for the UKMO and D-ANN models for all target months. Both underperform 204 between September and December. To show the differences between the two models, the skills based on D-ANN were 205 subtracted from the UKMO outputs (Fig. 6(e-i)). Compared to the UKMO outputs, D-ANN performed poorly from October 206 to January but was more skillful across the spring and summer months. For lead times exceeding 30 days, D-ANN has a clear 207 advantage. However, the correlation skills varied considerably among the regions, with higher skills in the east and south 208 regions compared to the north.

(a)

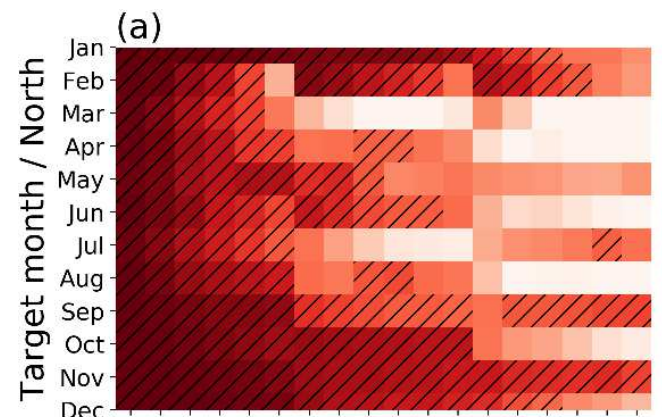

(b)
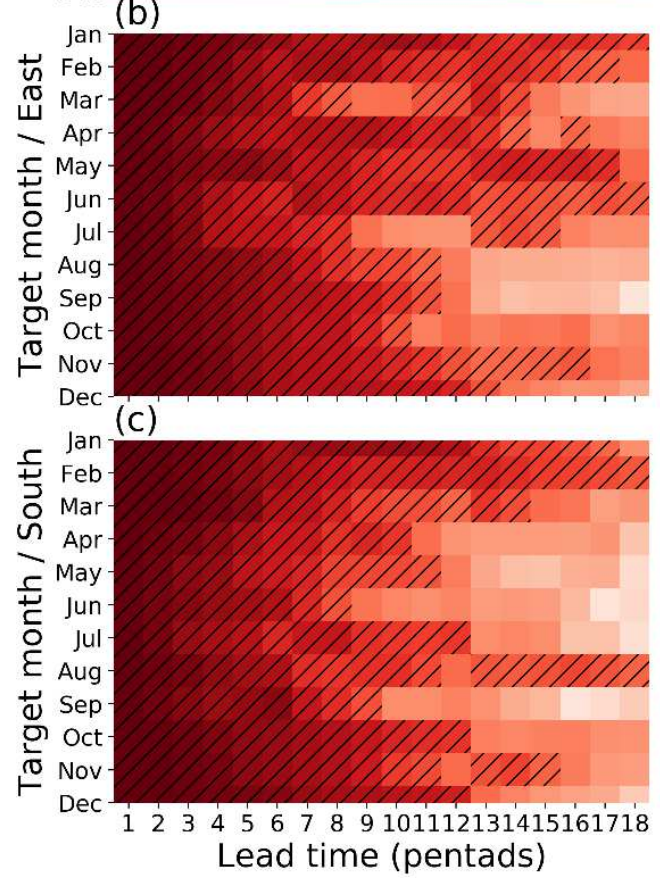

(d)

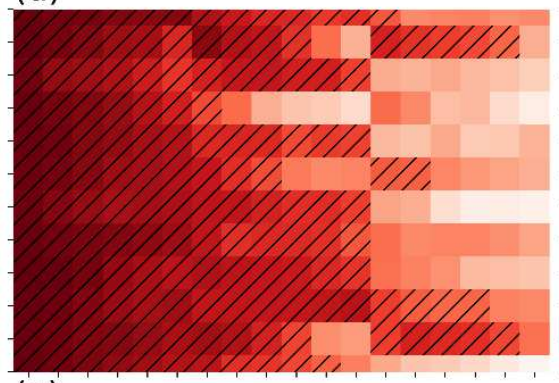

(e)

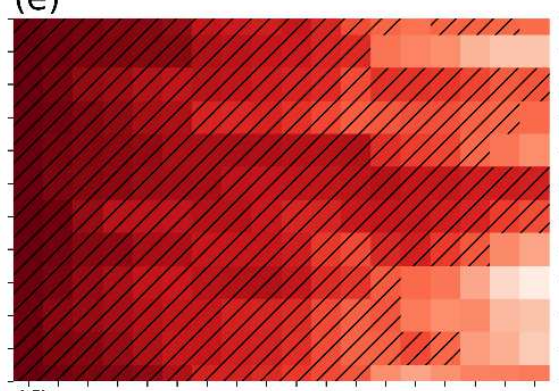

(f)

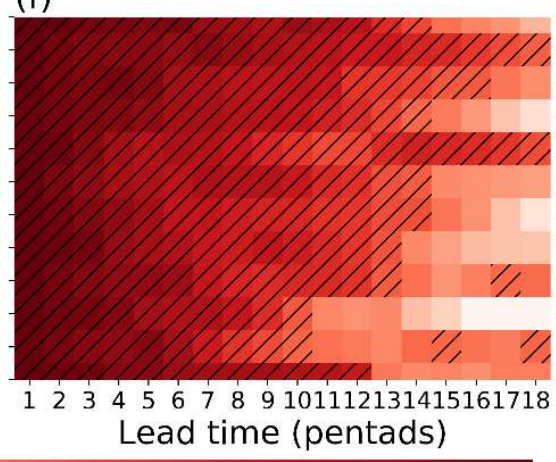

(e)

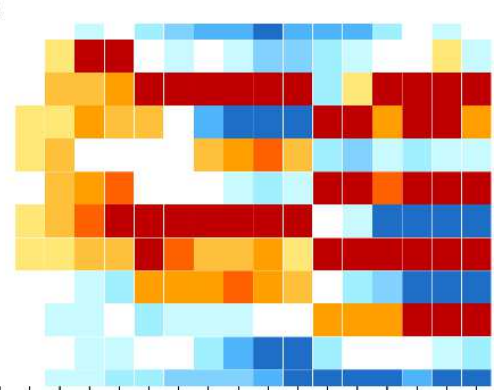

('h)

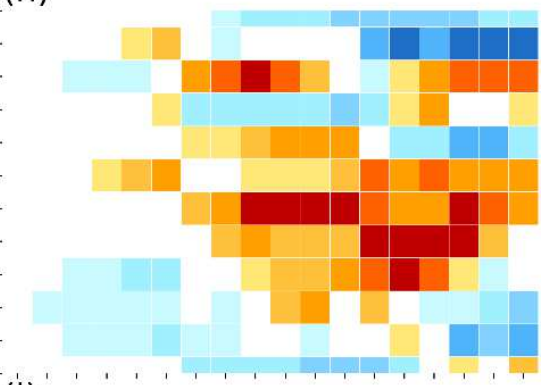

(i)

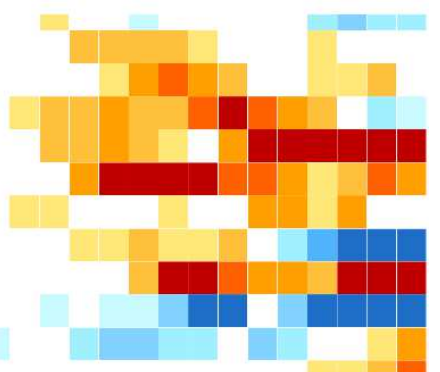

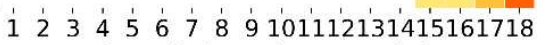
Lead time (pentads) Correlation Skill

0.7

0.8 0.9

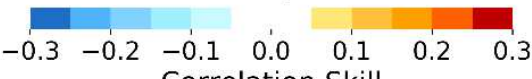

Fig. 6 Comparison of the correlation skills of UKMO and D-ANN models in different target months in the study regions: a-c are Corr(UKMO), d-f are Corr(D-ANN), and e-i are Corr(D-ANN) - Corr(UKMO). Shaded areas represent Corr > 0.5. Horizontal coordinates indicate different lead times (pentads); the first pentad includes the 1-5-day predictions, the second includes 6-10-day predictions, and so on. Vertical coordinates are target months 
215 Fig. 7(a-c) shows that D-ANN can effectively predict seasonal droughts across the different regions. The color maps (Fig.

$2167(\mathrm{~d}-\mathrm{e})$ ) quantify the contribution of each grid predictor to the prediction, where positive and negative indicate that the predictor 217 contributes to positive and negative to SPI3, respectively.

218 The representative regions identified by the RF for GH850 and SLP are mainly located in the east and south of the Tibetan 219 Plateau and the Northwest Pacific. In addition, the representative regions in the north are sparser than in the east and south, 220 which means the RF could not effectively extract key information from the atmospheric variables. Importantly, the East Asian 221 Summer/Winter Monsoons are fundamental factors affecting droughts and floods in China (Ding et al. 2008; Wen et al. 2000; 222 Yihui and Chan 2005; Zhou and Wu 2010). Interestingly, the representative regions were almost exclusively located in those 223 areas where the CDC calculates the East Asian Summer/Winter Monsoons Indices (http://cmdp.ncc224 cma.net/Monitoring/monsoon.htm). Further details of these indices are provided by Shi and Zhu (1996) and Zhang et al. (2003).

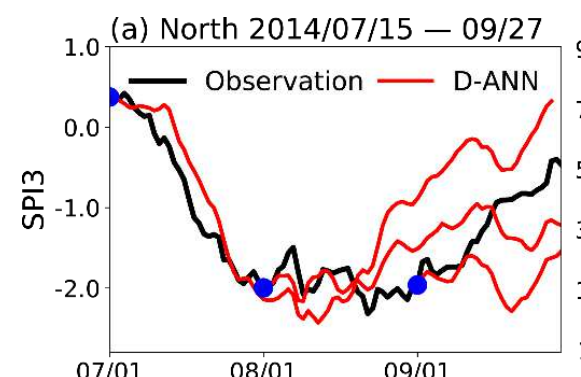

(b) East 2013/03/14 - /05/15

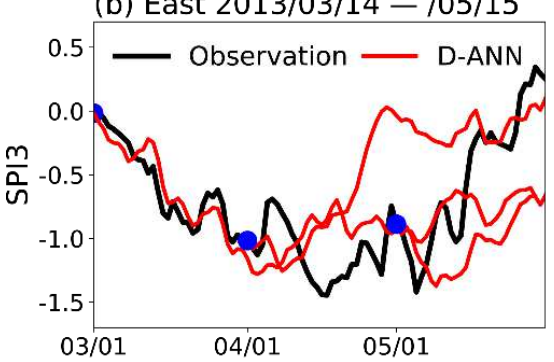

(c) South 2009/01/31 - 04/19

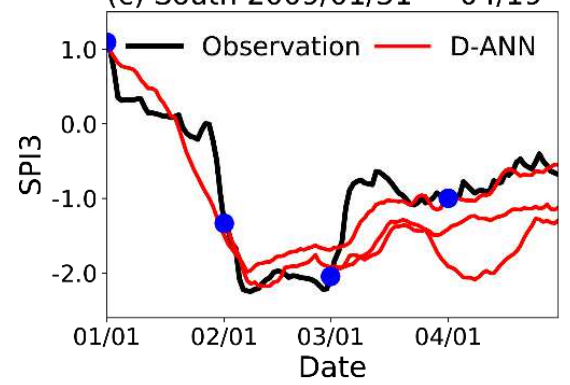

(d) GH850 / North

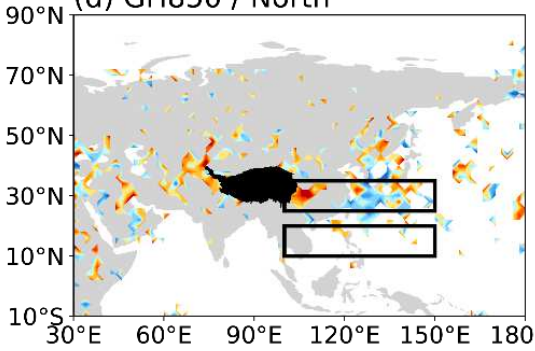

(e) GH850 / East

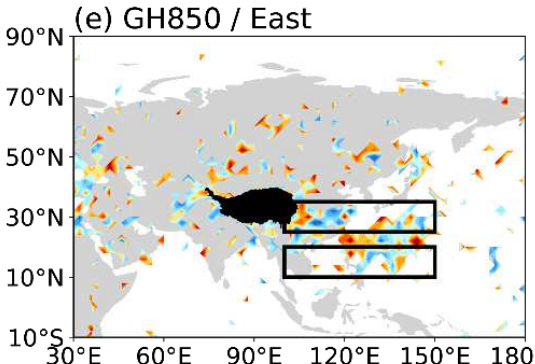

(f) GH850 / South

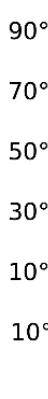

Fig. 7 Interpretations of the physical mechanisms of the D-ANN model: a-c, three droughts in the north, east, and south regions (black and red curves represent observations and D-ANN predictions, respectively, and blue dots are initial prediction moments); d-i, colors represent the contribution of the D-ANN model extracted from each grid, with positive values in red and negative values in blue; $d-f$, the two black boxes $\left(10^{\circ}-20^{\circ} \mathrm{N}, 100^{\circ}-150^{\circ} \mathrm{E}\right.$ and $\left.25^{\circ}-35^{\circ} \mathrm{N}, 100^{\circ}-150^{\circ} \mathrm{E}\right)$ show the calculation areas of $\mathrm{East}^{-}$ 


\subsection{Predicting drought process}

233 We divided individual drought periods into three phases of onset, persistence, and relief. For example, for the drought from

23415 July 2014 to 27 September 2014, the onset, persistence, and relief periods correspond to 15 July-09 August, 10 August-3

235 September, and 4 September-27 September, respectively. Fig. 8 shows the analysis of all droughts in the east study region

236 from 1993 to 2016, and results for the north and south regions are included in Supplement 4.

237 The UKMO and D-ANN models showed different prediction abilities for all drought phases. Importantly, effective prediction 238 of the onset phases of droughts is crucial for drought resistance. The UKMO model performed better for lead times $<45$ days, 239 while D-ANN performed better with lead times $>45$ days. For the drought persistence phase, D-ANN always produced better 240 predictions, with correlation values of 0.59 with a 60-day lead time, indicating that this model is better at predicting drought 241 intensity. However, D-ANN predictions during the relief phases of droughts were poorer with lead times $>45$ days, which 242 likely reflects the requirement for large precipitation inputs during this phase.
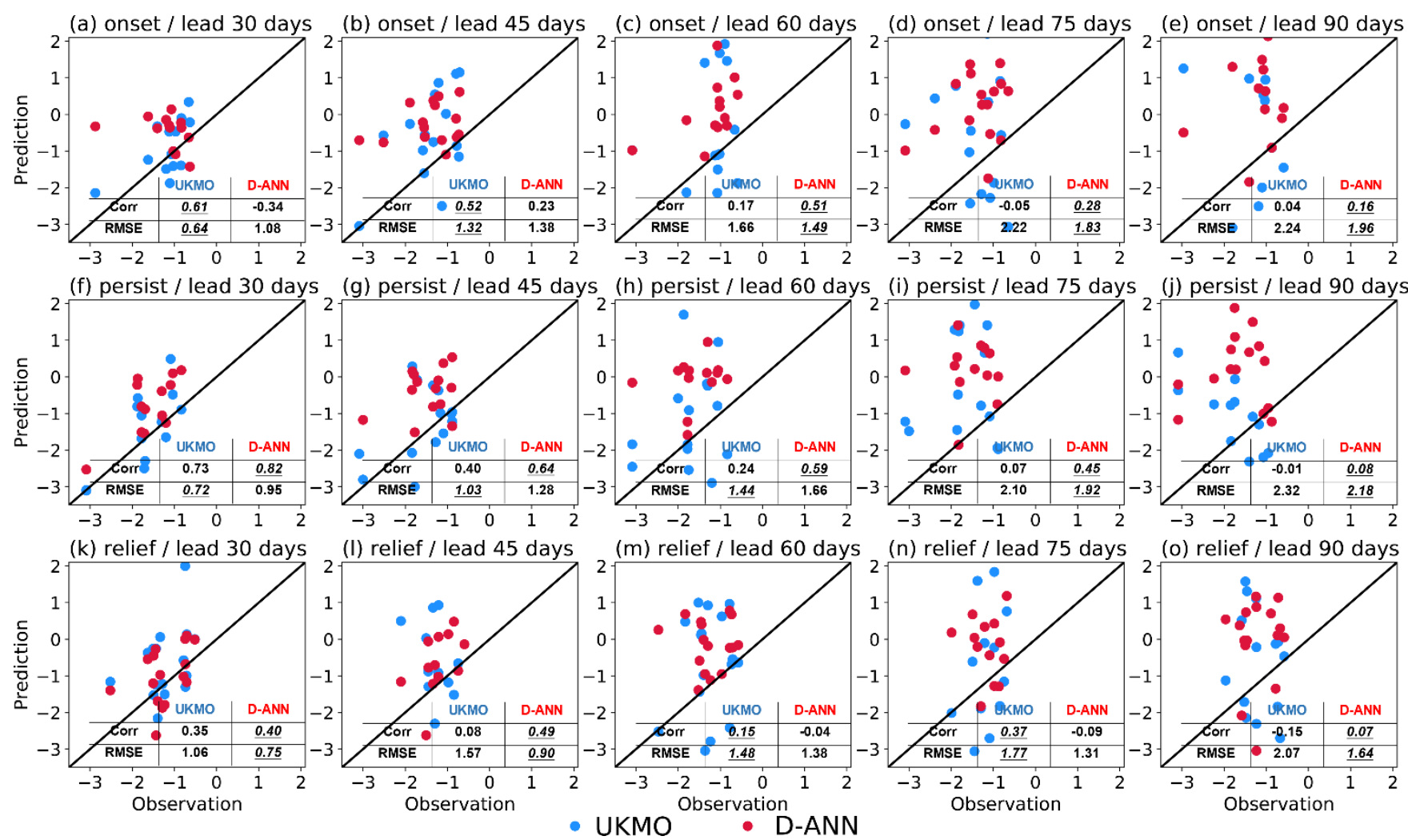

Fig. 8 Predictions of drought phases with different lead times (days) in the east study region of China: UKMO and D-ANN outputs are shown in blue and red, respectively; a-e, drought onset phase; $\mathbf{f}-\mathbf{j}$, drought persistence phase; $k-0$, drought relief phase. Corr and RMSE represent correlation coefficient and root-mean-square error, respectively 


\subsection{Network structure}

249 All of our results are based on the single-layer, 16-node ANN model described in Sect. 3. In this discussion, we focus on two 250 important parameters in the ANN model, namely the number of layers and nodes.

\section{5.1.1 Hidden layer nodes: more or less?}

252 If hidden layer nodes are too few, it is difficult for a network to learn and acquire information-processing capabilities. 253 Conversely, too many nodes in a hidden layer result in over-fitting (Zou et al. 2009). We trained the model by modifying the 254 hidden nodes in the network while maintaining the number of layers at 1, the results of which are shown in Table 3. We found 255 that when fewer than 16 nodes are used, model performance was compromised, and when more than 16 nodes are included, 256 the model provides greater complexity but does not out-perform the validation dataset.

257 Table 3 Performance of the ANN model with different numbers of nodes

\begin{tabular}{|c|c|c|c|c|c|c|c|}
\hline \multirow{2}{*}{ Regions } & \multirow{2}{*}{ Metrics } & & \multicolumn{5}{|c|}{ Nodes } \\
\hline & & & 4 & 8 & 16 & 32 & 64 \\
\hline \multirow{4}{*}{ North } & \multirow{2}{*}{ Corr } & Training & 0.84 & 0.95 & 0.97 & 0.95 & $\underline{0.98}$ \\
\hline & & Validation & 0.69 & 0.70 & $\underline{0.74}$ & 0.70 & $\overline{0.70}$ \\
\hline & \multirow[t]{2}{*}{ RMSE } & Training & 0.58 & 0.33 & $\overline{0.25}$ & 0.31 & 0.22 \\
\hline & & Validation & 0.67 & 0.65 & 0.64 & 0.66 & $\overline{0.66}$ \\
\hline \multirow{4}{*}{ East } & \multirow{2}{*}{ Corr } & Training & 0.83 & 0.95 & 0.96 & 0.97 & 0.93 \\
\hline & & Validation & 0.82 & 0.83 & 0.86 & $\overline{0.85}$ & 0.82 \\
\hline & \multirow{2}{*}{ RMSE } & Training & 0.60 & 0.34 & 0.31 & 0.24 & 0.37 \\
\hline & & Validation & 0.61 & 0.61 & 0.55 & 0.58 & 0.58 \\
\hline \multirow{4}{*}{ South } & \multirow{2}{*}{ Corr } & Training & 0.94 & 0.94 & $\overline{0.96}$ & 0.95 & 0.93 \\
\hline & & Validation & 0.76 & 0.77 & $\overline{0.78}$ & $\underline{0.78}$ & 0.77 \\
\hline & \multirow{2}{*}{ RMSE } & Training & 0.36 & 0.35 & $\overline{0.28}$ & $\overline{0.32}$ & 0.39 \\
\hline & & Validation & 0.68 & 0.69 & $\overline{0.65}$ & 0.66 & 0.64 \\
\hline
\end{tabular}

\section{5.1.2 Hidden layers: deep or shallow?}

259 The neural network learns from the data through the nodes in each layer, and the stacking of multiple layers allows the structure 260 of complex applications to be learned (Pan 2019). However, it remains questionable a deeper network (i.e. with more layers) 261 produced a stronger model (Tan 2020). To test this, keeping the number of nodes at 16, we varied the number of layers, as 262 shown in Table 4. Based on this, we found that network performance did not improve as the number of layers was increased. 263 From the analyses in Sec. 5.1.1 and Sec. 5.1.2, we found that the relationship between contemporaneous atmospheric 264 circulation parameters and regional meteorological drought may not be overly complex, meaning that a single-layer, 16-node 265 ANN model was able to effectively represent nonlinear relationships.

266 Table 4 Performance of ANN models with different numbers of layers

\begin{tabular}{llccc}
\hline \multirow{2}{*}{ Regions } & \multirow{2}{*}{ Metrics } & \multicolumn{3}{c}{ Layers } \\
\cline { 3 - 4 } & & 1 & 2 & 3 \\
\hline
\end{tabular}




\begin{tabular}{cccccc}
\hline \multirow{4}{*}{ North } & \multirow{2}{*}{ Corr } & Training & 0.97 & 0.97 & $\mathbf{0 . 9 8}$ \\
& & Validation & $\underline{\mathbf{0 . 7 4}}$ & 0.70 & 0.73 \\
& \multirow{2}{*}{ RMSE } & Training & 0.25 & 0.30 & $\mathbf{0 . 1 9}$ \\
& & Validation & 0.64 & 0.65 & $\mathbf{0 . 6 3}$ \\
\hline \multirow{4}{*}{ East } & \multirow{2}{*}{ Corr } & Training & 0.96 & 0.95 & $\mathbf{0 . 9 8}$ \\
& & Validation & $\underline{\mathbf{0 . 8 6}}$ & 0.77 & 0.82 \\
& \multirow{2}{*}{ RMSE } & Training & $\underline{\mathbf{0 . 3 1}}$ & 0.39 & $\mathbf{0 . 3 1}$ \\
& & Validation & $\underline{\mathbf{0 . 5 5}}$ & 0.67 & 0.69 \\
\hline \multirow{4}{*}{ South } & \multirow{2}{*}{ Corr } & Training & 0.96 & 0.81 & $\mathbf{0 . 9 8}$ \\
& & Validation & $\underline{\mathbf{0 . 7 8}}$ & 0.65 & 0.75 \\
& \multirow{2}{*}{ RMSE } & Training & 0.28 & 0.62 & $\underline{\mathbf{0 . 2 4}}$ \\
& & Validation & $\underline{\mathbf{0 . 6 5}}$ & 0.78 & $\mathbf{0 . 7 2}$ \\
\hline
\end{tabular}

\subsection{Impact of forecast error from the ECMWF dataset}

\section{5.2.1 Anomaly correlation coefficients (ACC) of forecasted atmospheric variables}

269 We used the forecasted atmospheric circulation dataset from the ECMWF as a predictor to force the hybrid models. Therefore,

270 the models contained two kinds of error, first from the ML models and, second, from the GCM. This section focuses on the

271 impact of the second error source. Fig. 9 shows that the ACC of all variables decreased with increasing lead time, which

272 indicates that the error from the ECMWF dataset introduced a lot of uncertainty to the prediction. Indeed, forecasting skills

273 are almost entirely lost for lead times above 50 days.
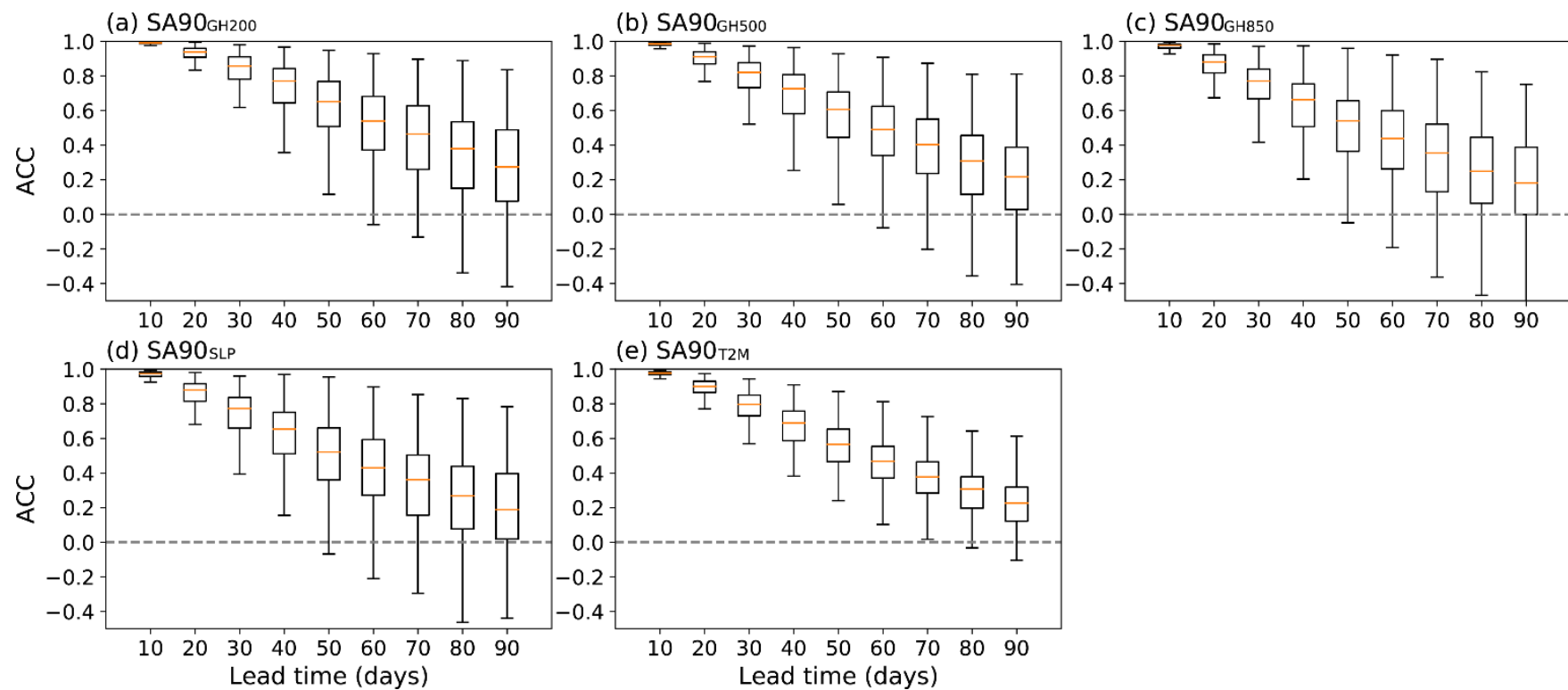

Fig. 9 Boxplots of $\mathrm{ACC}$ for all atmospheric variables $\left(30^{\circ}-180^{\circ} \mathrm{E}, 10^{\circ} \mathrm{S}-90^{\circ} \mathrm{N}\right)$ with increasing lead times. The top to bottom five

lines of a box plot represent the minimum, first quartile, median, third quartile, and maximum values of data, respectively

\subsubsection{Perfect drought prediction}

278 We replaced all of the atmospheric data for the prospective 90 days with reanalysis data to re-force the hybrid models, which 279 we named 'Perfect-D-Lasso' and 'Perfect-D-ANN' (Fig. 10). The correlation skills of the Perfect hybrid models were almost 
always above 0.8. Moreover, the performance of the models differed between the study regions, with the Perfect-D-ANN model performing best in the north region. Methods for post-processing GCM precipitation outputs have also been included in the dynamical-statistical prediction methods (Schepen et al. 2016), and so it is necessary to correct the forecasted atmospheric variables accordingly.
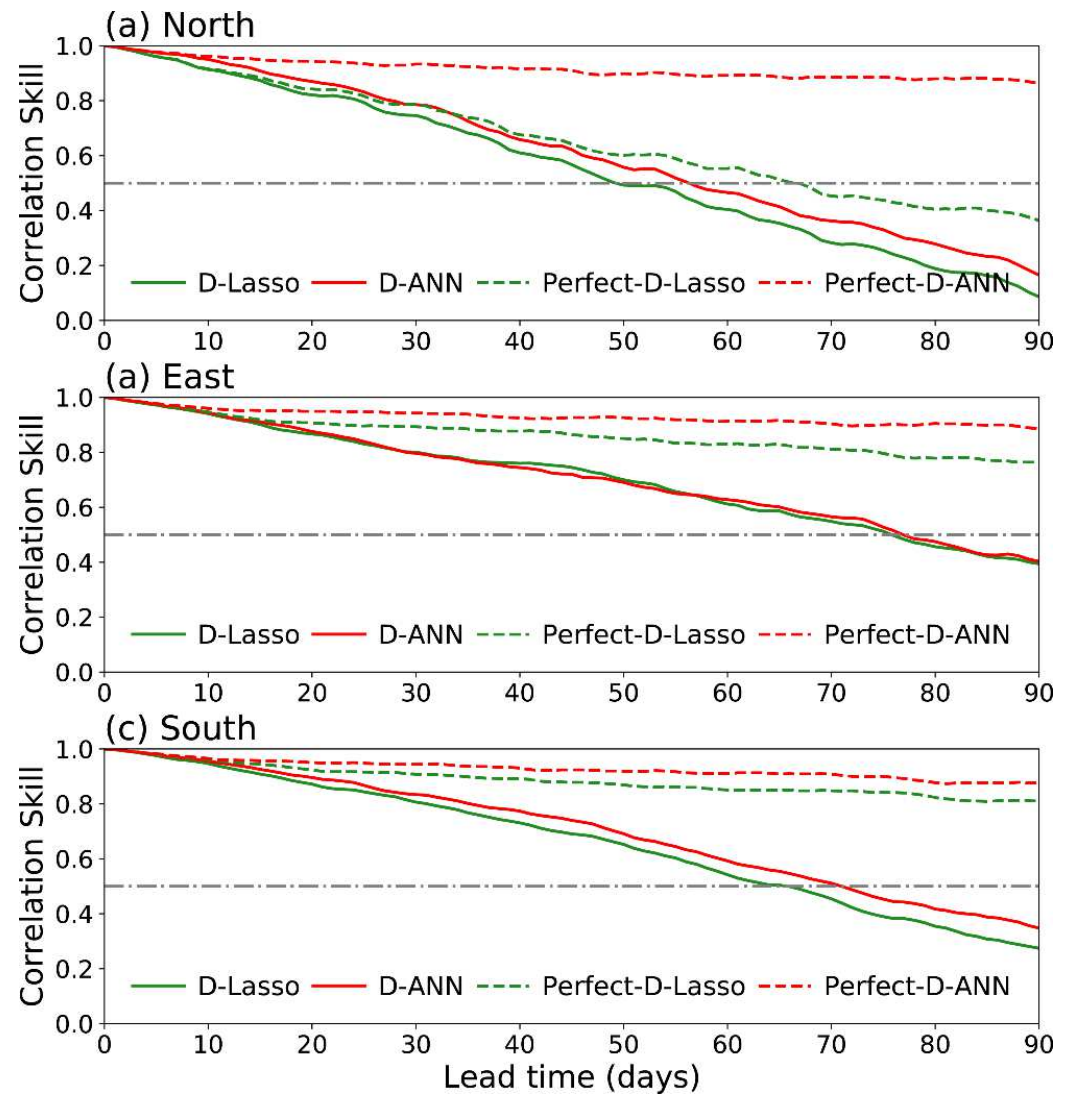

Fig. 10 Correlation skills of four models predicting the SPI3 with different lead times in the different study regions. The solid green curves represent D-Lasso model predictions; the solid red curves represent D-ANN model predictions; the dashed green curves represent Perfect-D-Lasso model predictions; and the dashed red curves represent the Perfect-D-ANN model predictions. The dashed grey lines indicate a correlation of 0.5

\section{Conclusions}

290 Seasonal drought prediction is important for drought resistance and water resources management. Here, we constructed 291 seasonal drought prediction models with atmospheric variables (GH200, GH500, GH850, T2M, and SLP) as predictors and 292 the SPI3 as the predictand. The resulting models were applied and evaluated for the prediction of meteorological droughts in north, east, and south regions of China. The main conclusions can be summarized as follows: (1) the daily-updated SPI3 was used to identify droughts for the last 40 years in the three drought regions; (2) the five-layer atmospheric variables were processed as model predictors; (3) the Lasso and ANN models were trained using the ERA5 reanalysis dataset for the period 
1980-2011 and validated for the period 2012-2019, demonstrating good model robustness; (4) hybrid models (D-Lasso and

D-ANN) were constructed by combining the ECMWF and ML models; (5) month-by-month drought prediction was performed for the period between 1993 and 2016. Compared to the dynamical models (Météo France, ECMWF, and UKMO), D-ANN not only extended the forecast skill horizons in all regions but offers higher predictive abilities in spring and summer; (6) we quantified the contribution of representative regions extracted using a RF approach, finding that these areas mainly correspond to those areas where the CDC calculates the East Asian Summer/Winter Monsoon indices; and (7) the D-ANN model is more skillful at predicting the onset and persistence phases of drought but performs comparatively poorly during the relief phase. Important limitations of this study are that the selected predictors fail to incorporate the precursors of drought, such as sea surface temperature, sea ice, and plateau snow cover (Li et al. 2018a; Schubert et al. 2016; Wang et al. 2017), and second, the atmospheric variable outputs from the ECMWF model could not be adequately post-processed.

\section{Declarations}

Competing interests The authors declare no competing interests.

Availability of data and material All the datasets used in this paper are publicly accessible.

Authors' contributions ZW, with the help of $\mathrm{HY}$ and $\mathrm{HH}$, designed the research. ZW and $\mathrm{HH}$ obtained the funding supporting it. ZW conducted case analysis and wrote the original draft. HY, HH, and YL jointly reviewed the entire manuscript. All authors finally read and approved the paper.

\section{Consent for publication Not applicable}

\section{Acknowledgments}

This work is supported by National Natural Science Foundation of China (grants No. 51779071); National Key Research and Development Program of China (Grants No. 2017YFC1502403 and 2018YFC0407701).

\section{References}

Agana N, Homaifar A (2017) A Deep Learning Based Approach for Long-Term Drought Prediction. doi:10.1109/SECON.2017.7925314 Ayantobo OO, Li Y, Song S, Yao N (2017) Spatial comparability of drought characteristics and related return periods in mainland China over 1961-2013 Journal of Hydrology 550:549-567 doi:https://doi.org/10.1016/j.jhydrol.2017.05.019

Buizza R, Leutbecher M (2015) The forecast skill horizon Quarterly Journal of the Royal Meteorological Society 141:3366-3382

Cai R, Tan H, Kontoyiannis H (2017) Robust surface warming in offshore China Seas and its relationship to the East Asian Monsoon wind field and ocean forcing on interdecadal time scales Journal of Climate 30:8987-9005 
Chen S, Zhang L, Liu X, Guo M, She D (2018) The Use of SPEI and TVDI to Assess Temporal-Spatial Variations in Drought Conditions in the Middle and Lower Reaches of the Yangtze River Basin, China Advances in Meteorology 2018:9362041 doi:10.1155/2018/9362041

China Meteorological Administration (2011) China Meteorological Disaster Yearbook (CMDY) China Meteorological Disaster Yearbook vol 978-7-5029-5446-8. Meteorological Press, Beijing, China

China Meteorological Administration (2014) China Meteorological Disaster Yearbook (CMDY) China Meteorological Disaster Yearbook vol 978-7-5029-5556-4. Meteorological Press, Beijing, China

Conforti P, Ahmed S, Markova G (2018) Impact of disasters and crises on agriculture and food security, 2017

Costa-Cabral M, Rath JS, Mills WB, Roy SB, Bromirski PD, Milesi C (2016) Projecting and forecasting winter precipitation extremes and meteorological drought in California using the North Pacific high sea level pressure anomaly Journal of Climate 29:5009-5026

Ding Y, Wang Z, Sun Y (2008) Inter-decadal variation of the summer precipitation in East China and its association with decreasing Asian summer monsoon. Part I: Observed evidences International Journal of Climatology: A Journal of the Royal Meteorological Society 28:1139-1161

Duan W, He B, Takara K, Luo P, Nover D, Yamashiki Y, Huang W (2014) Anomalous atmospheric events leading to Kyushu's flash floods, July 11-14, 2012 Natural Hazards 73:1255-1267

Hao Z, Hao F, Xia Y, Singh VP, Hong Y, Shen X, Ouyang W (2016) A statistical method for categorical drought prediction based on NLDAS-2 Journal of Applied Meteorology and Climatology 55:1049-1061

Hao Z, Singh V, Xia Y (2018) Seasonal Drought Prediction: Advances, Challenges, and Future Prospects Reviews of Geophysics 56 doi:10.1002/2016rg000549

Hart RE, Grumm RH (2001) Using Normalized Climatological Anomalies to Rank Synoptic-Scale Events Objectively Monthly Weather Review 129:2426-2442

Jin D, Guan Z, Tang W (2013) The Extreme Drought Event during Winter-Spring of 2011 in East China: Combined Influences of Teleconnection in Midhigh Latitudes and Thermal Forcing in Maritime Continent Region Journal of Climate 26:8210-8222 doi:10.1175/JCLI-D-12-00652.1

Khan N, Sachindra DA, Shahid S, Ahmed K, Shiru MS, Nawaz N (2020) Prediction of droughts over Pakistan using machine learning algorithms Advances in Water Resources 139:103562

Kirtman B, Anderson D, Brunet G, Kang I-S, Scaife AA, Smith D (2013) Prediction from weeks to decades. In: Climate science for serving society. Springer, pp 205-235

Lang Y, Luo L, Ye A, Duan Q (2020) Do CFSv2 Seasonal Forecasts Help Improve the Forecast of Meteorological Drought over Mainland China? Water 12:2010

Lang Y et al. (2014) Evaluating Skill of Seasonal Precipitation and Temperature Predictions of NCEP CFSv2 Forecasts over 17 Hydroclimatic Regions in China Journal of Hydrometeorology 15:1546-1559

Lavaysse C, Vogt J, Toreti A, Carrera ML, Pappenberger F (2018) On the use of weather regimes to forecast meteorological drought over Europe Nat Hazards Earth Syst Sci 18:3297-3309 doi:10.5194/nhess-18-3297-2018

Lhotka O, Trnka M, Kyselý J, Markonis Y, Balek J, Možný M (2020) Atmospheric circulation as a factor contributing to increasing drought severity in Central Europe Journal of Geophysical Research: Atmospheres 125:e2019JD032269

Li H, Chen H, Wang H, Sun J, Ma J (2018a) Can Barents Sea ice decline in spring enhance summer hot drought events over northe astern China? Journal of Climate 31:4705-4725

Li Q, Yang S, Wu T, Liu X (2017) Subseasonal Dynamical Prediction of East Asian Cold Surges Weather \& Forecasting 32

Li X, Li D, Li X, Chen L (2018b) Prolonged seasonal drought events over northern China and their possible causes International Journal of Climatology 38:4802-4817

Li Y, Wu Z, He H, Wang QJ, Xu H, Lu G (2020) Post-processing sub-seasonal precipitation forecasts at various spatiotemporal scales across China during boreal summer monsoon Journal of Hydrology:125742 doi:https://doi.org/10.1016/j.jhydrol.2020.125742

Liu Y, Huang R (2019) Linkages between the south and east asian monsoon water vapor transport during boreal summer Journal of Climate 32:4509-4524

Liu Z, Lu G, He H, He J (2018) A conceptual prediction model for seasonal drought processes using atmospheric and oceanic standardized anomalies: application to regional drought processes in China Hydrology and Earth System Sciences 22:529-546

Liu Z, Lu G, He H, Wu Z, He J (2017) Anomalous features of water vapor transport during severe summer and early fall droughts in Southwest China Water 9:244

Liu Z, Törnros T, Menzel L (2016) A probabilistic prediction network for hydrological drought identification and environmental flow assessment Water Resources Research 52:6243-6262

Ma F, Yuan X, ye A (2015) Seasonal Drought Predictability and Forecast Skill over China Journal of Geophysical Research: Atmospheres 120:n/a-n/a doi:10.1002/2015JD023185

Ma S, Zhu C, Liu J (2020) Combined Impacts of Warm Central Equatorial Pacific Sea Surface Temperatures and Anthropogenic Warming on the 2019 Severe Drought in East China Advances in Atmospheric Sciences 37:1149-1163 doi:10.1007/s00376-020-0077-8 
Madadgar S, Aghakouchak A, Shukla S, Wood AW, Cheng L, Hsu K-L, Svoboda M (2016) A hybrid statistical-dynamical framework for meteorological drought prediction: Application to the southwestern United States Water Resources Research 52:5095-5110

Merryfield WJ et al. (2020) Current and emerging developments in subseasonal to decadal prediction Bulletin of the American Meteorological Society 101:E869-E896

Mo KC, Lyon B (2015) Global Meteorological Drought Prediction Using the North American Multi-Model Ensemble Journal of Hydrometeorology 16:1409-1424 doi:10.1175/JHM-D-14-0192.1

Okumura YM, DiNezio P, Deser C (2017) Evolving impacts of multiyear La Niña events on atmospheric circulation and US drought Geophysical Research Letters 44:11-614

Pan B (2019) Advancing Precipitation Prediction Using a Composite of Models and Data

Pan B, Anderson GJ, Goncalves A, Lucas DD, Bonfils CJW, Lee J (2020) Improving seasonal forecast using probabilistic deep learning arXiv preprint arXiv:201014610

Reichstein M, Camps-Valls G, Stevens B, Jung M, Denzler J, Carvalhais N, Prabhat M (2019) Deep learning and process understanding for data-driven Earth system science Nature 566:195 doi:10.1038/s41586-019-0912-1

Rezaeianzadeh M, Tabari H (2012) MLP-based drought forecasting in different climatic regions Theoretical and Applied Climatology 109 doi:10.1007/s00704-012-0592-3

Ribeiro AFS, Pires CAL (2016) Seasonal drought predictability in Portugal using statistical-dynamical techniques Physics and Chemistry of the Earth, Parts A/B/C 94:155-166

Richardson D, Fowler H, Kilsby C, Neal R, Dankers R (2020) Improving sub-seasonal forecast skill of meteorological drought: a weather pattern approach Natural Hazards and Earth System Sciences 20:107-124 doi:10.5194/nhess-20-107-2020

Schepen A, Wang QJ, Robertson DE (2016) Application to Post-processing of Meteorological Seasonal Forecasting. In: Duan Q, Pappenberger F, Thielen J, Wood A, Cloke HL, Schaake JC (eds) Handbook of Hydrometeorological Ensemble Forecasting. Springer Berlin Heidelberg, Berlin, Heidelberg, pp 1-29. doi:10.1007/978-3-642-40457-3_18-1

Schubert SD et al. (2016) Global meteorological drought: a synthesis of current understanding with a focus on SST drivers of precipitation deficits Journal of Climate 29:3989-4019

Shi N, Zhu Q (1996) An abrupt change in the intensity of the East Asian summer monsoon index and its relationship with temperature and precipitation over East China International Journal of Climatology: A Journal of the Royal Meteorological Society 16:757-764

Svoboda M, Hayes M, Wood D (2012) Standardized precipitation index user guide World Meteorological Organization Geneva, Switzerland Tan T (2020) Are Deeper Networks Better? —A Case Study. https://towardsdatascience.com/are-deeper-networks-better-a-case-study$6 \mathrm{ee} 9 \mathrm{bcb} 0725 \mathrm{~b}$.

Ujeneza EL, Abiodun BJ (2015) Drought regimes in Southern Africa and how well GCMs simulate them Climate Dynamics 44:1595-1609

Wang C, Yang K, Li Y, Wu D, Bo Y (2017) Impacts of spatiotemporal anomalies of Tibetan Plateau snow cover on summer precipitation in eastern China Journal of Climate 30:885-903

Wang Q et al. (2014) Temporal-spatial characteristics of severe drought events and their impact on agriculture on a global scale Quaternary International 349:10-21

Wang QJ, Schepen A, Robertson DE (2012) Merging seasonal rainfall forecasts from multiple statistical models through Bayesian model averaging Journal of Climate 25:5524-5537

Wen C, Graf HF, Ronghui H (2000) The interannual variability of East Asian Winter Monsoon and its relation to the summer monsoon Advances in Atmospheric Sciences 17:48-60 doi:10.1007/s00376-000-0042-5

World Health Organization (2019) Drought. https://www.who.int/health-topics/drought.

Xu L, Chen N, Zhang X (2018a) A comparison of large-scale climate signals and the North American Multi-Model Ensemble (NMME) for drought prediction in China Journal of Hydrology 557:378-390 doi:https://doi.org/10.1016/j.jhydrol.2017.12.044

Xu L, Chen N, Zhang X, Chen Z (2018b) An evaluation of statistical, NMME and hybrid models for drought prediction in China Journal of Hydrology 566:235-249

Yan H, Moradkhani H, Zarekarizi M (2017) A probabilistic drought forecasting framework: A combined dynamical and statistical approach Journal of Hydrology 548:291-304 doi:https://doi.org/10.1016/j.jhydrol.2017.03.004

Yihui D, Chan JCL (2005) The East Asian summer monsoon: an overview Meteorology and Atmospheric Physics 89:117-142 doi:10.1007/s00703-005-0125-z

Yoo-Geun H, Jeong-Hwan K, Jing-Jia L (2019) Deep learning for multi-year ENSO forecasts Nature 573

Zhang Q, Tao S, Chen L (2003) Interannual variation of East Asian Summer Monsoon index and East Asian atmospheric circulation Acta Meteorologica Sinica:559-568

Zhang R (2015) Changes in East Asian summer monsoon and summer rainfall over eastern China during recent decades Science Bulletin 60:1222-1224 doi:10.1007/s11434-015-0824-X

Zhang R, Chen Z-Y, Xu L-J, Ou C-Q (2019) Meteorological drought forecasting based on a statistical model with machine learning techniques in Shaanxi province, China Science of The Total Environment 665:338-346

Zhou LT, Wu R (2010) Respective impacts of the East Asian winter monsoon and ENSO on winter rainfall in China Journal of Geophysical Research: Atmospheres 115 
Zhu Q, Luo Y, Zhou D, Xu Y-P, Wang G, Tian Y (2020) Drought prediction using in situ and remote sensing products with SVM over the Xiang River Basin, China Natural Hazards doi:10.1007/s11069-020-04394-x

Zhuang Y, Fu R, Wang H (2020) Large-Scale Atmospheric Circulation Patterns Associated with US Great Plains Warm Season Droughts

Zou W, Li Y, Tang A (2009) Effects of the number of hidden nodes used in a structured-based neural network on the reliability of image classification Neural Computing and Applications 18:249-260 doi:10.1007/s00521-008-0177-3 


\section{Figures}

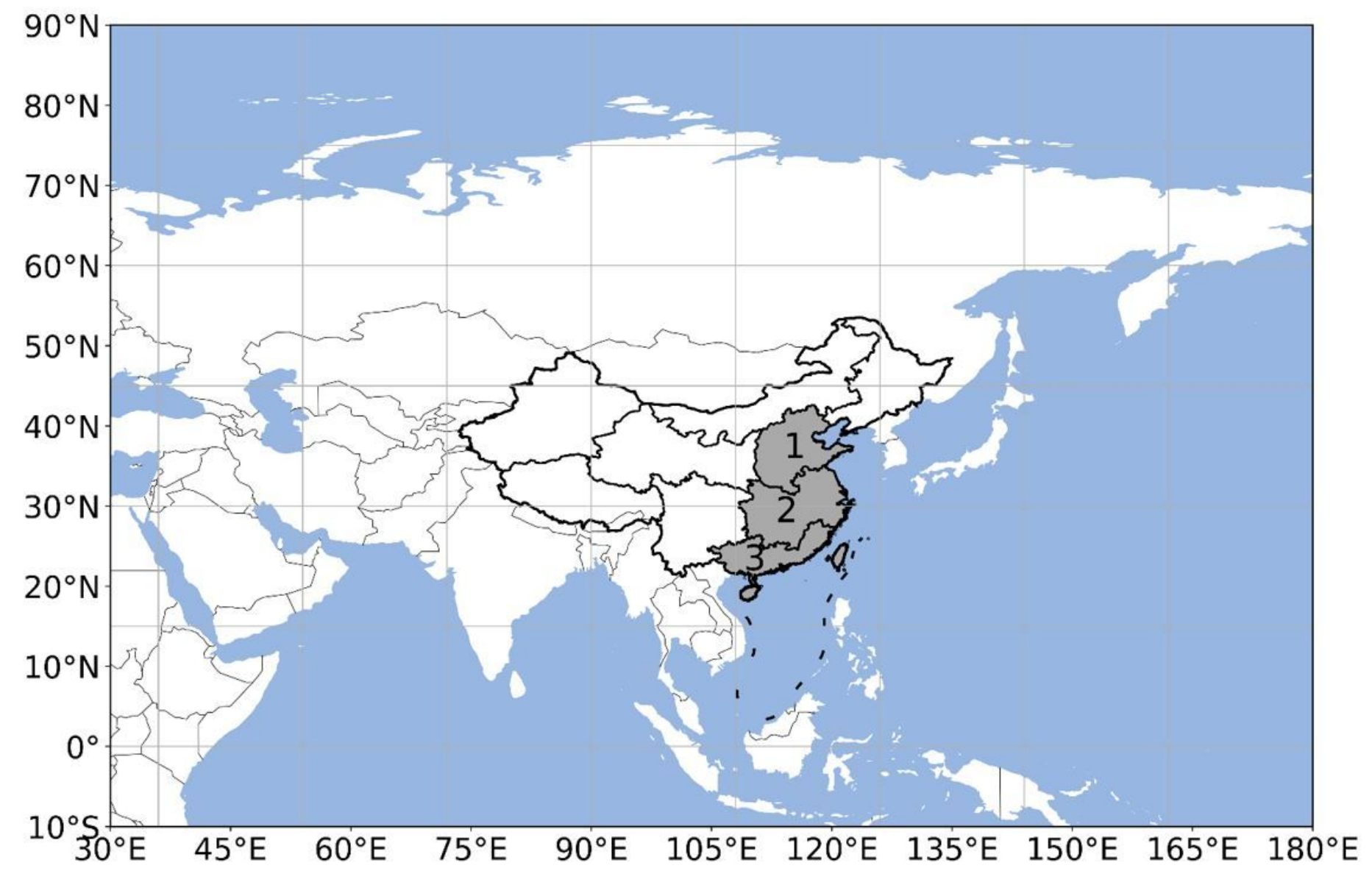

\section{Figure 1}

The location of the drought regions of China and the coverage of atmospheric variables $\left(30^{\circ}-180^{\circ} \mathrm{E}, 10^{\circ} \mathrm{S}-\right.$ $90^{\circ} \mathrm{N}$ ). The gray shaded areas are the study regions. 1-3 represent Northern, Eastern, and Southern China, respectively Note: The designations employed and the presentation of the material on this map do not imply the expression of any opinion whatsoever on the part of Research Square concerning the legal status of any country, territory, city or area or of its authorities, or concerning the delimitation of its frontiers or boundaries. This map has been provided by the authors. 


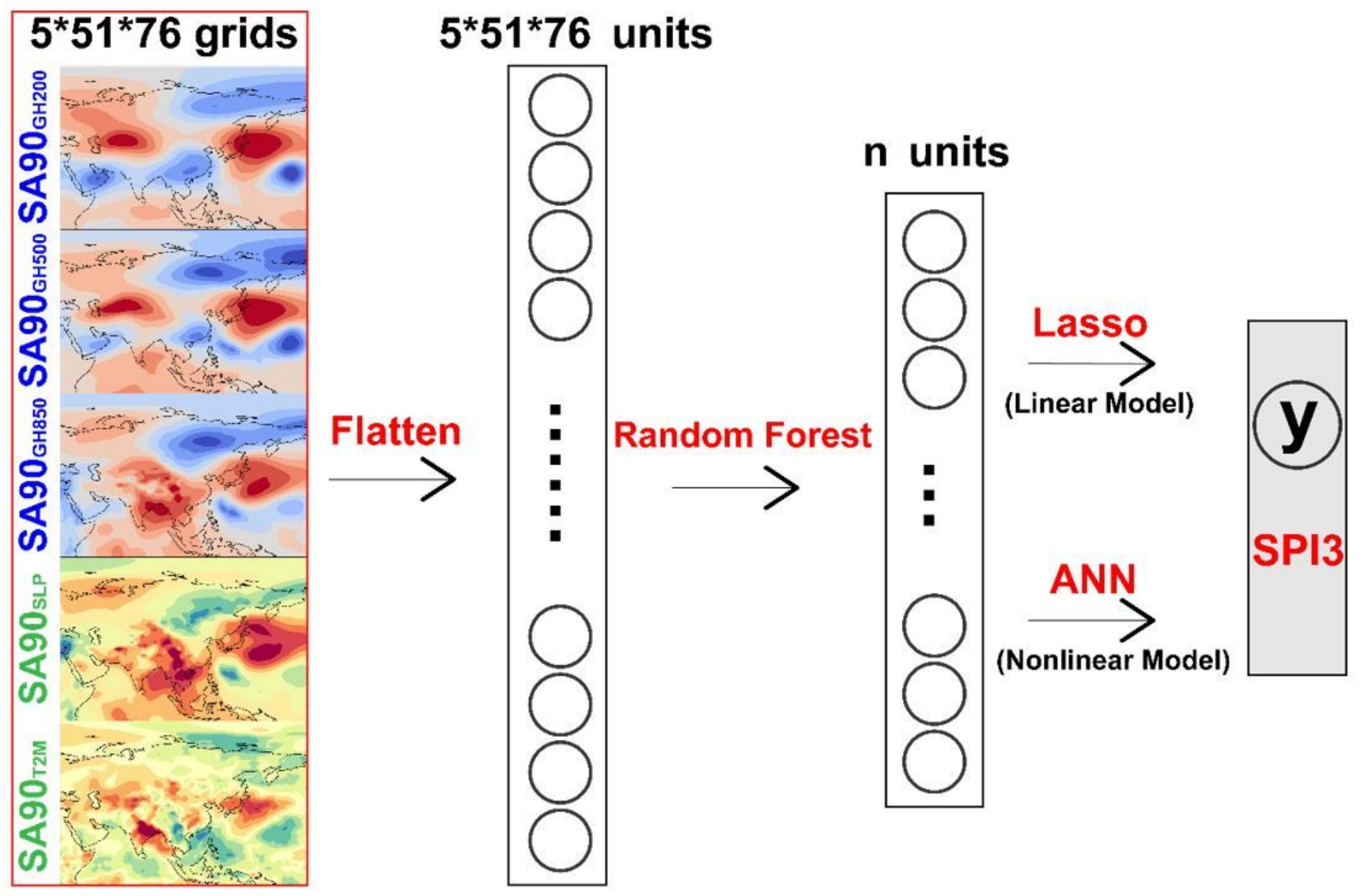

Figure 2

ML model structure, where ANN contains a single layer and 16 nodes. SA90GH200, SA90GH500, SA90GH850, SA90T2M, and SA90SLP are the 90-day standardized anomalies of GH200, GH500, GH850, SLP and T2M, respectively. Lasso is a linear model, while ANN is linear Note: The designations employed and the presentation of the material on this map do not imply the expression of any opinion whatsoever on the part of Research Square concerning the legal status of any country, territory, city or area or of its authorities, or concerning the delimitation of its frontiers or boundaries. This map has been provided by the authors.

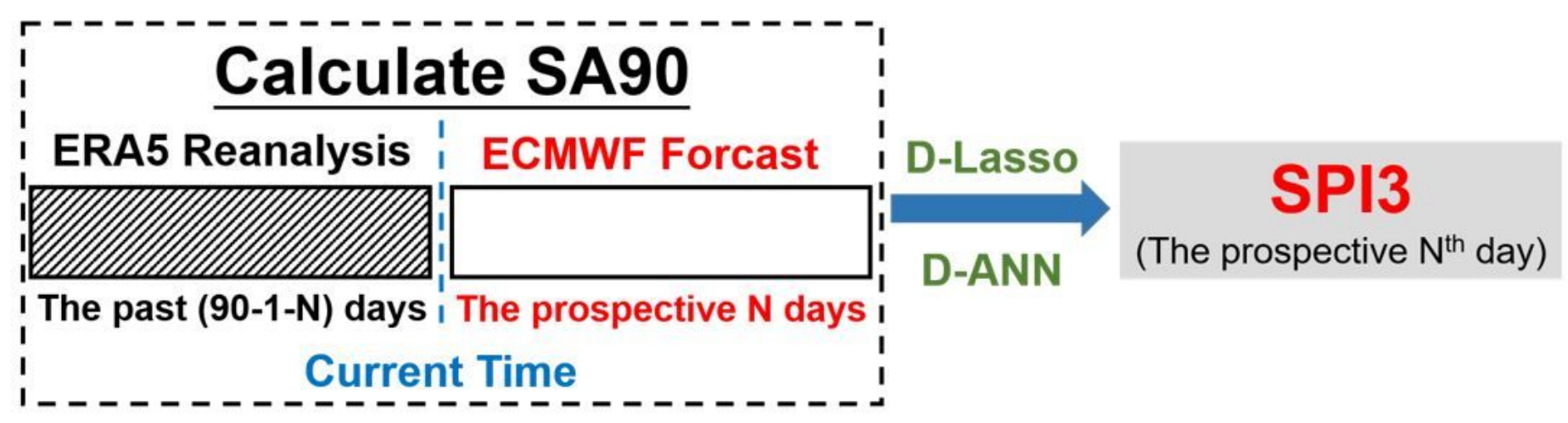

Figure 3 
Schematic representation of the calculation process for the prospective Nth-day SPI3
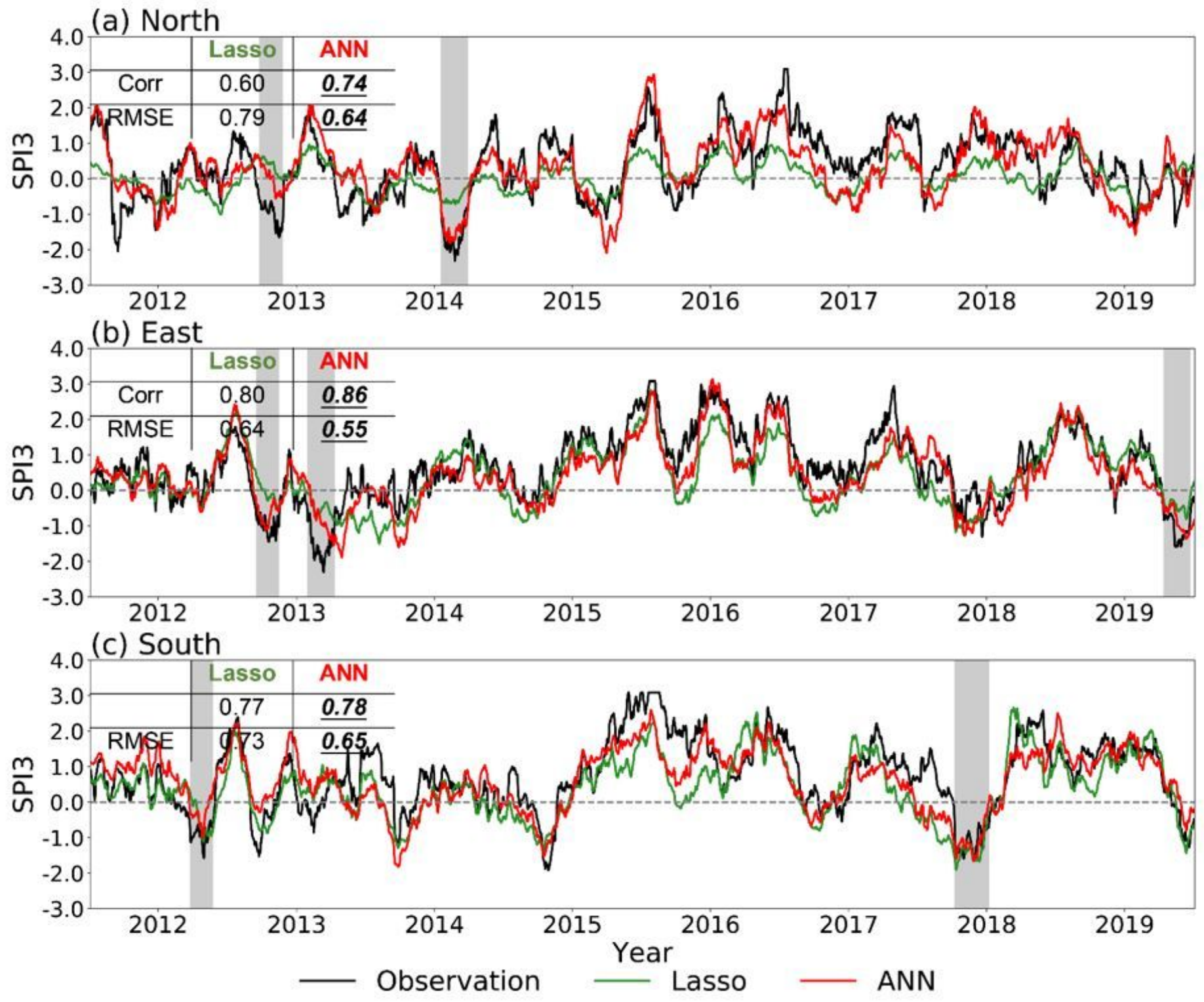

Figure 4

Temporal trends in the observed and simulated SPI3 during the validation period (1 January 2012 to 31 December 2019). The black curve is the observed SPI3, and green and red curves are the Lasso and ANN simulations, respectively. The grey shading shows the identified drought events in Sect. 4.1 

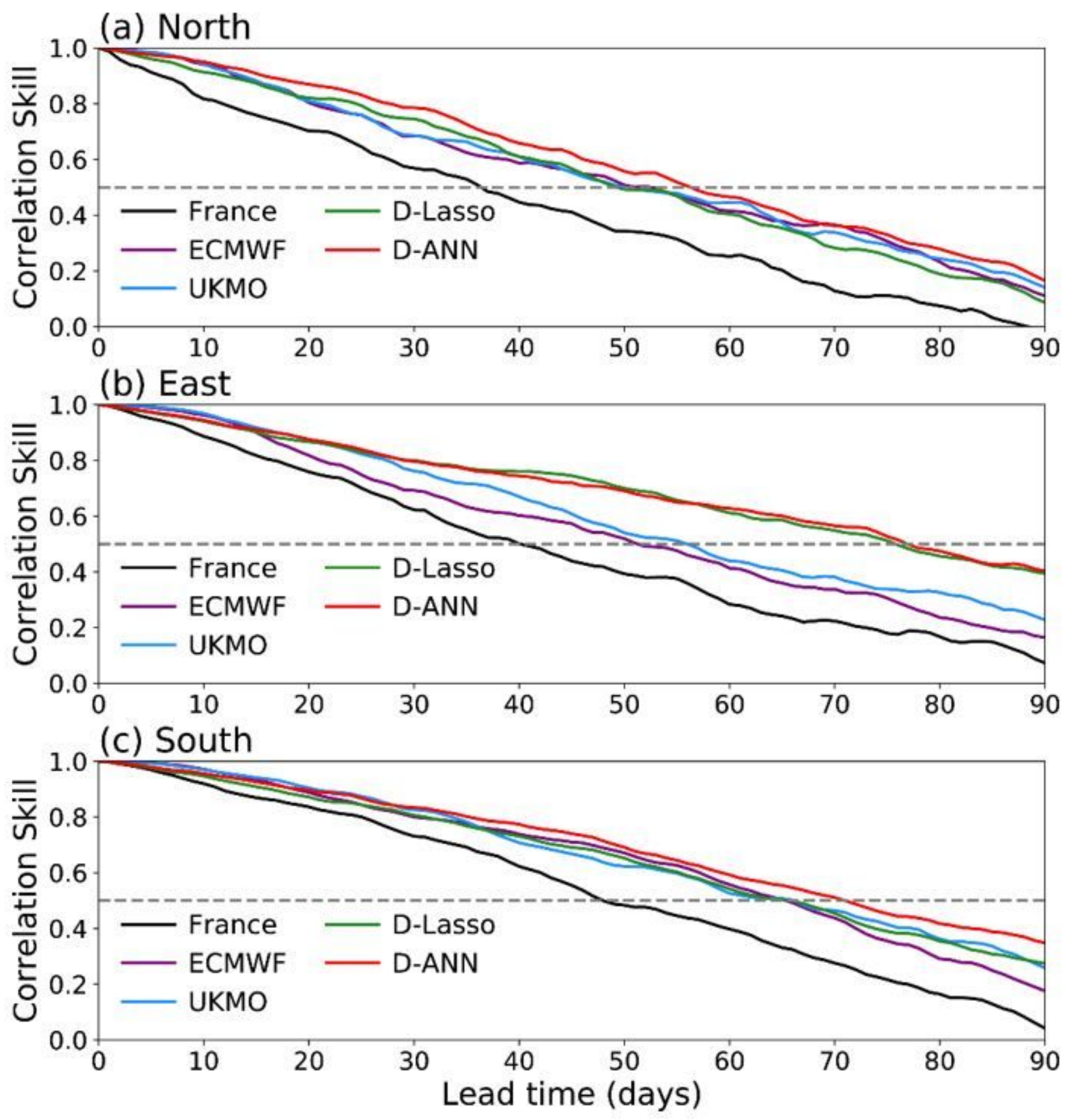

Figure 5

Correlation skills between five models predicting SPI3 at different lead times. Black, purple, blue, green, and red curves represent Météo France, ECMWF, UKMO, D-Lasso, and D-ANN outputs, respectively. The grey dashed lines indicate a correlation of 0.5 
(a)

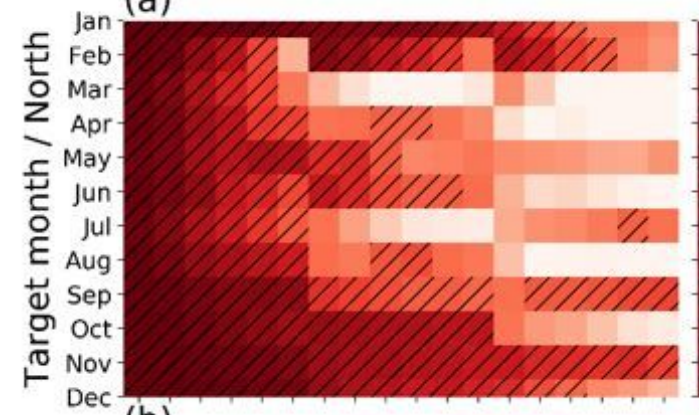

(b)

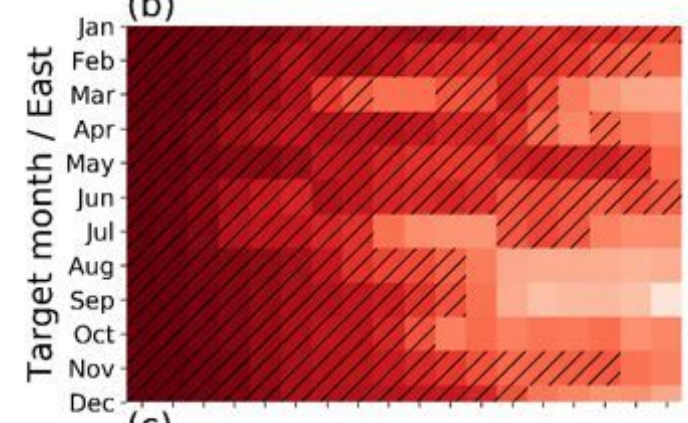

(c)

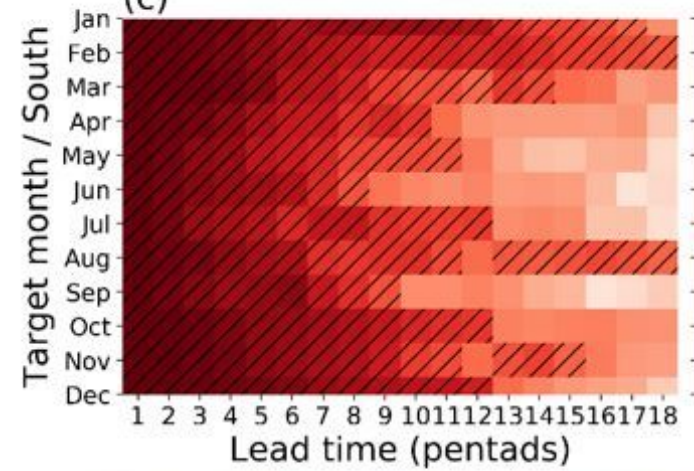

(d)

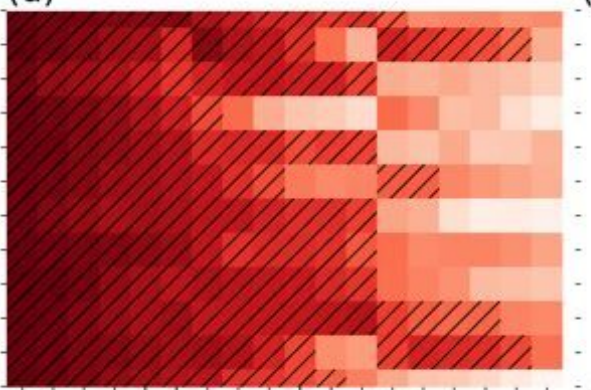

(e)

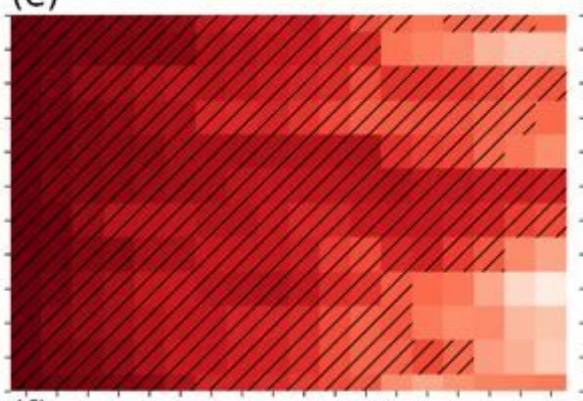

(f)

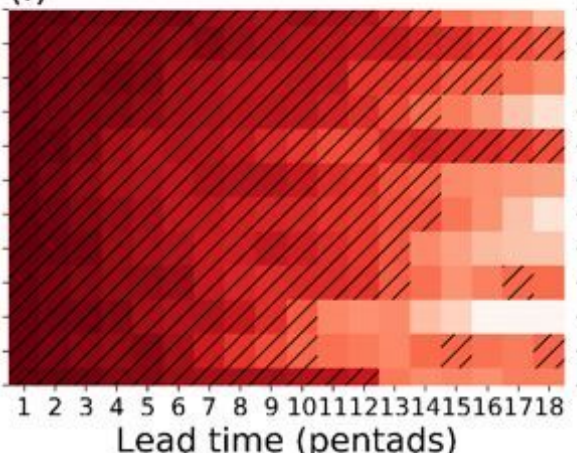

(e)

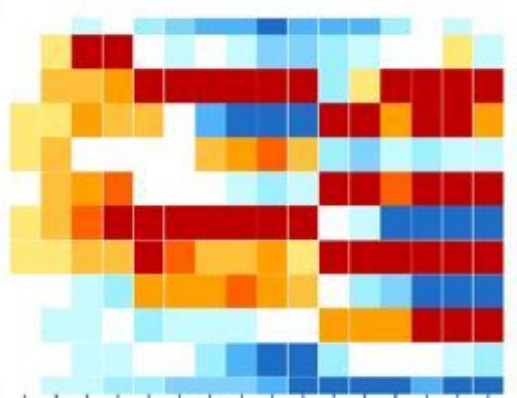

(h)

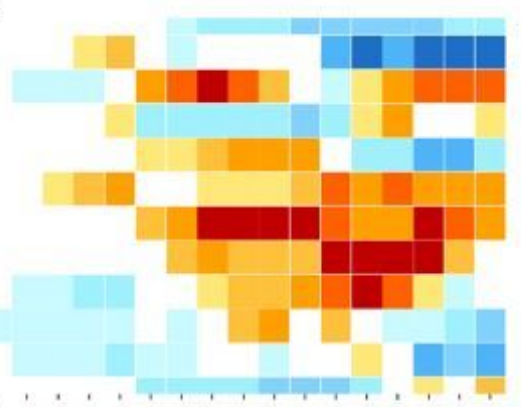

(i)

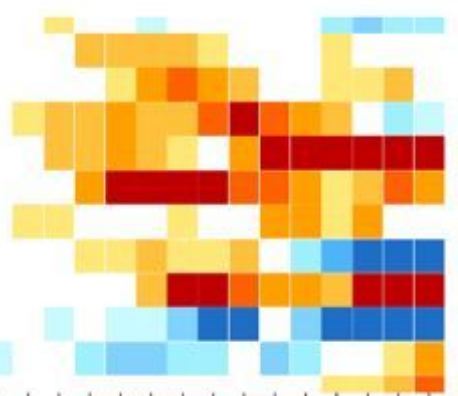

Lead time (pentads)

0.0

$\begin{array}{llllll}0.1 & 0.2 & 0.3 & 0.4 & 0.5 & 0 . \\ \text { Correlation Skill }\end{array}$

$\begin{array}{ll}0.7 & 0.8\end{array}$

0.9

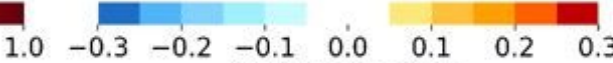

\section{Figure 6}

Comparison of the correlation skills of UKMO and D-ANN models in different target months in the study regions: a-c are Corr(UKMO), $d-f$ are Corr(D-ANN), and e-i are Corr(D-ANN) - Corr(UKMO). Shaded areas represent Corr $>0.5$. Horizontal coordinates indicate different lead times (pentads); the first pentad includes the 1-5-day predictions, the second includes 6-10-day predictions, and so on. Vertical coordinates are target months 


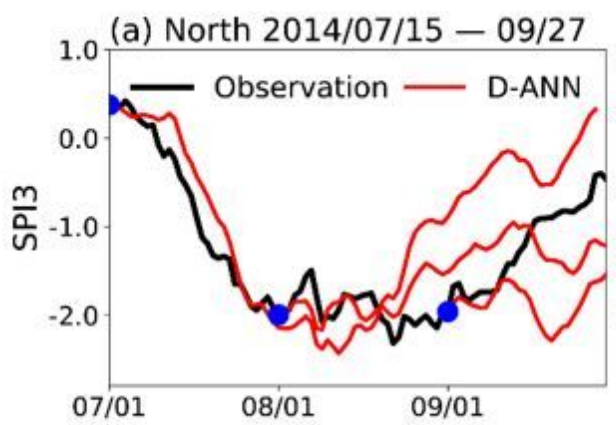

(b) East 2013/03/14 - /05/15

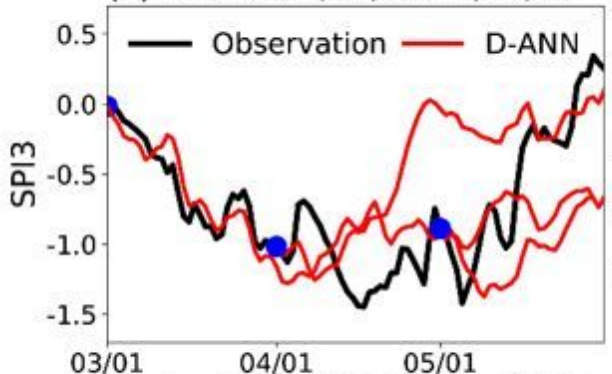

(c) South $2009 / 01 / 31-04 / 19$

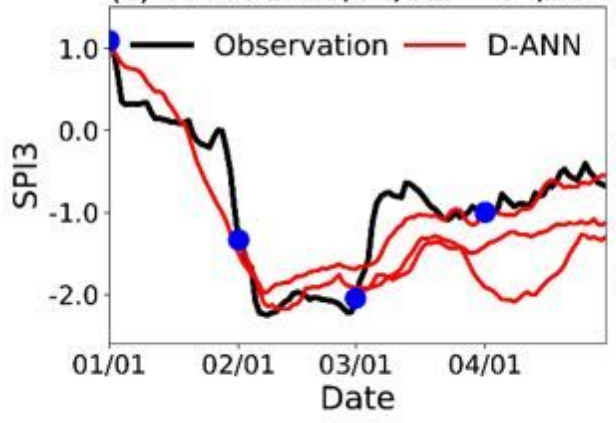

(d) GH850 / North

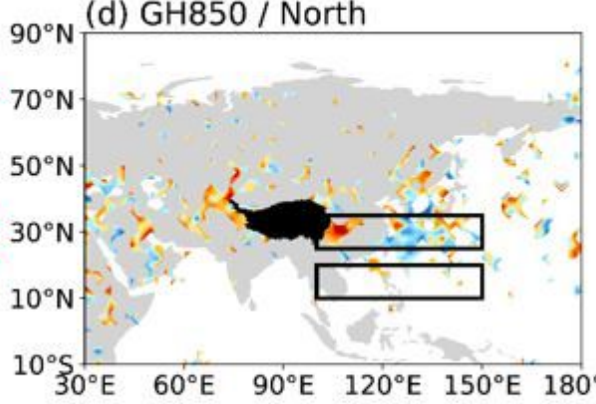

(e) GH850 / East

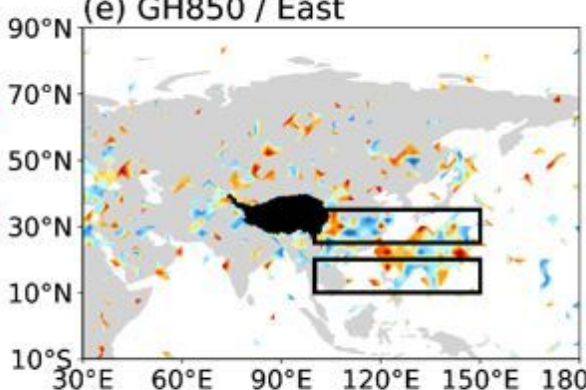

(f) GH850 / South

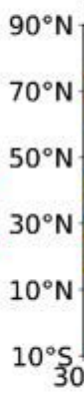

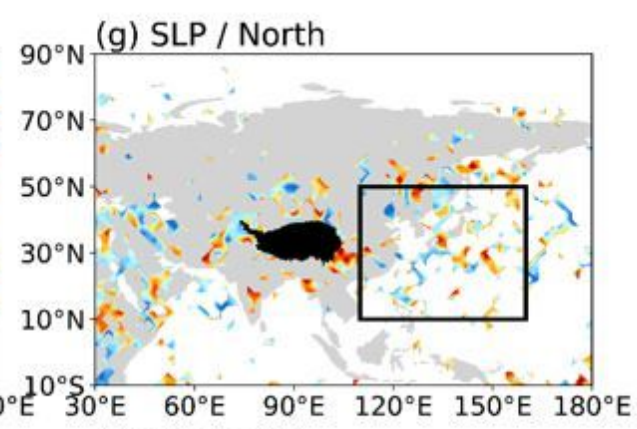
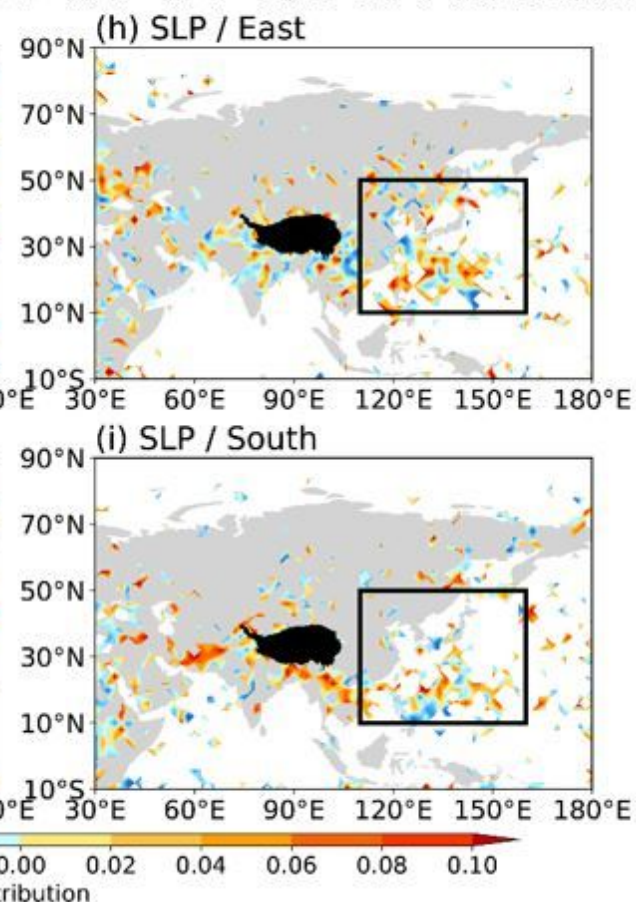

\section{Figure 7}

Interpretations of the physical mechanisms of the D-ANN model: a-c, three droughts in the north, east, and south regions (black and red curves represent observations and D-ANN predictions, respectively, and blue dots are initial prediction moments); $d-i$, colors represent the contribution of the D-ANN model extracted from each grid, with positive values in red and negative values in blue; $d-f$, the two black boxes $\left(10^{\circ}-20^{\circ} \mathrm{N}, 100^{\circ}-150^{\circ} \mathrm{E}\right.$ and $\left.25^{\circ}-35^{\circ} \mathrm{N}, 100^{\circ}-150^{\circ} \mathrm{E}\right)$ show the calculation areas of East Asian Summer Monsoon Index; $\mathrm{g}-\mathrm{i}$, the black box $\left(10^{\circ}-50^{\circ} \mathrm{N}, 110^{\circ}-160^{\circ} \mathrm{E}\right)$ shows the calculation area of East Asian Winter Monsoon Index Note: The designations employed and the presentation of the material on this map do not imply the expression of any opinion whatsoever on the part of Research Square concerning the legal status of any country, territory, city or area or of its authorities, or concerning the delimitation of its frontiers or boundaries. This map has been provided by the authors. 

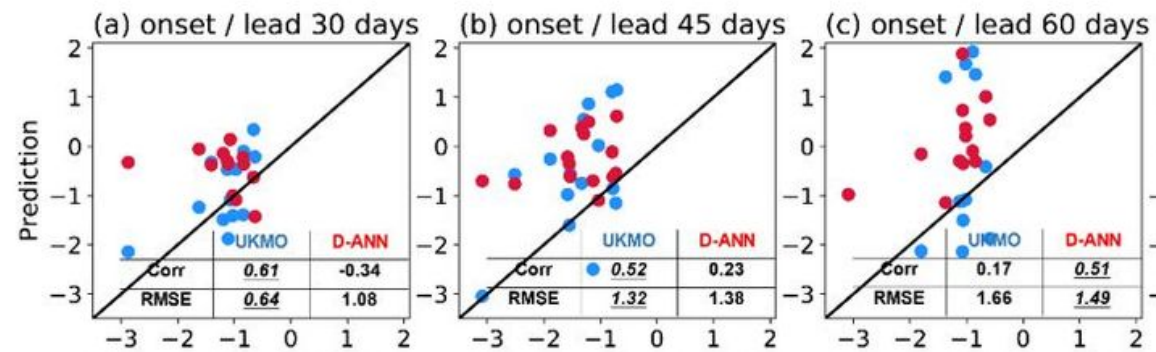

(d) onset / lead 75 days (e) onset / lead 90 days
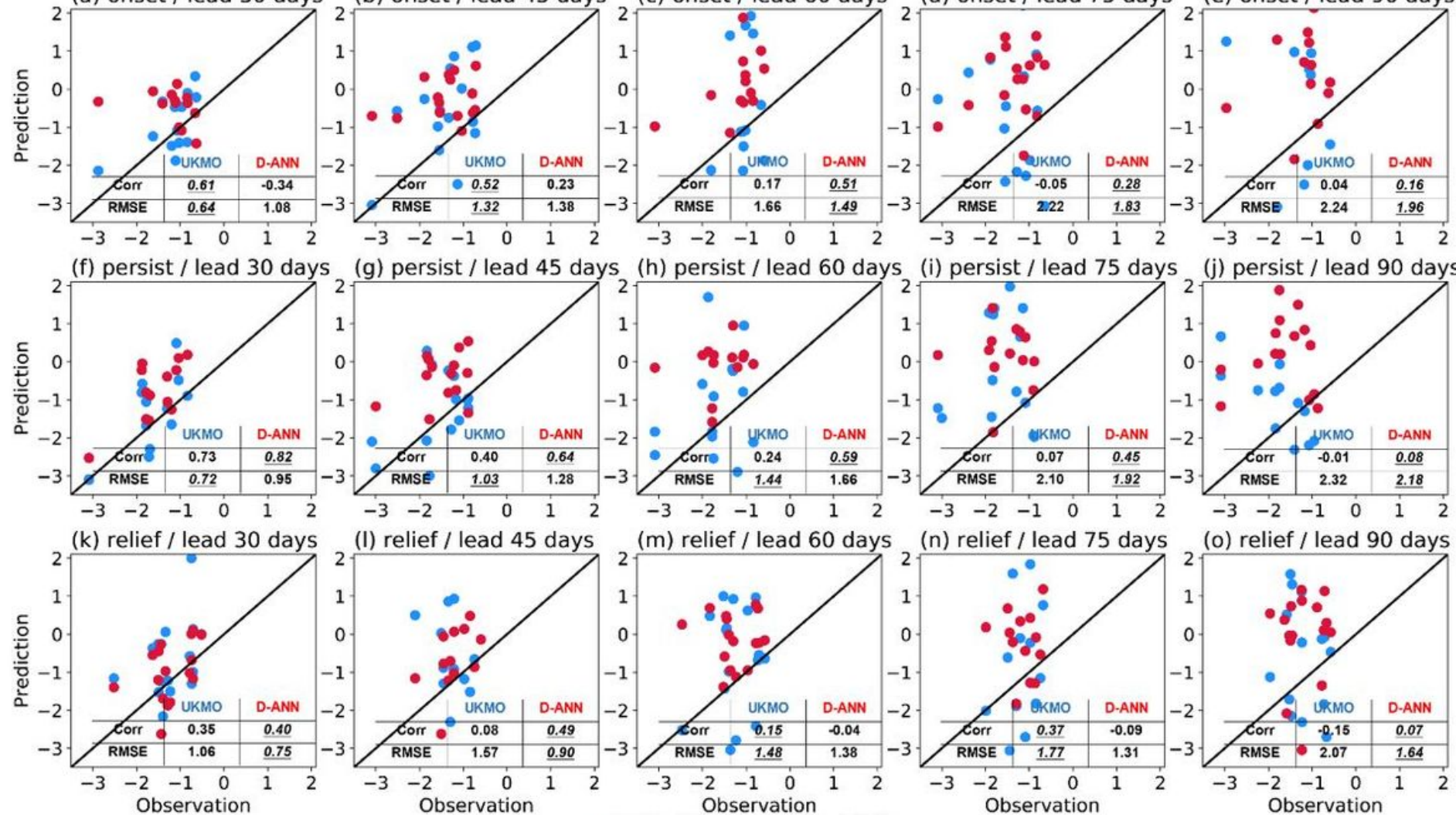

(m) relief $/$ ead 60 days
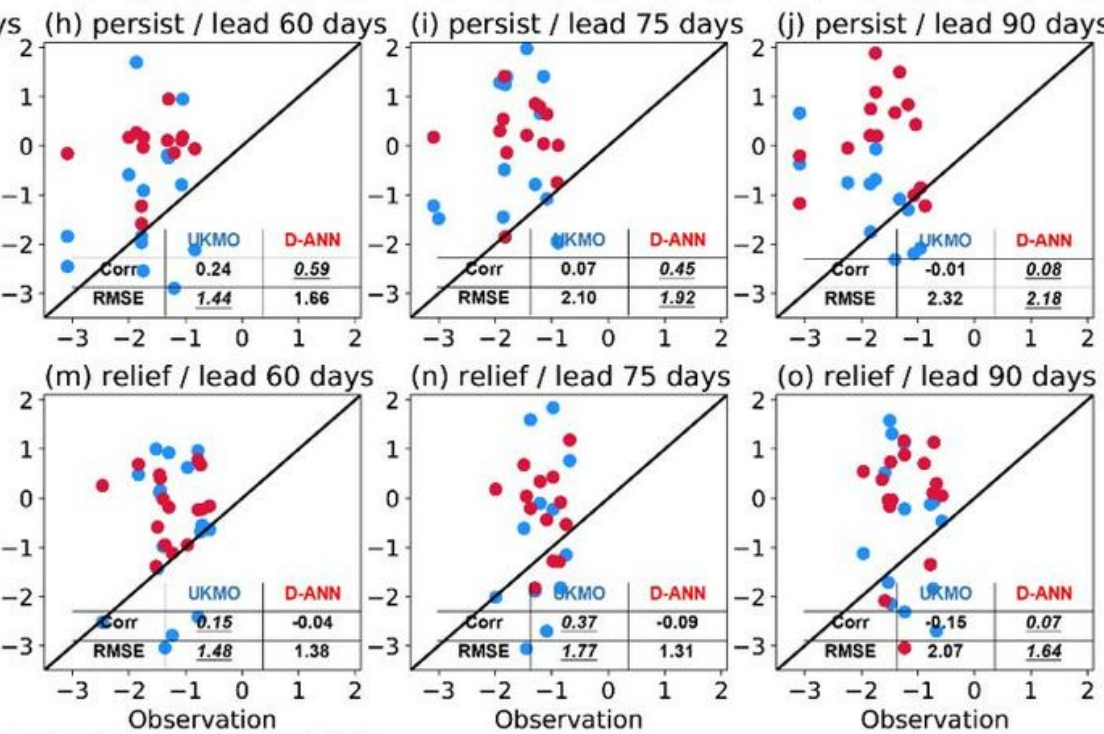

- UKMO

- D-ANN

\section{Figure 8}

Predictions of drought phases with different lead times (days) in the east study region of China: UKMO and D-ANN outputs are shown in blue and red, respectively; $a-e$, drought onset phase; $f-j$, drought persistence phase; $\mathrm{k}-\mathrm{o}$, drought relief phase. Corr and RMSE represent correlation coefficient and rootmean-square error, respectively
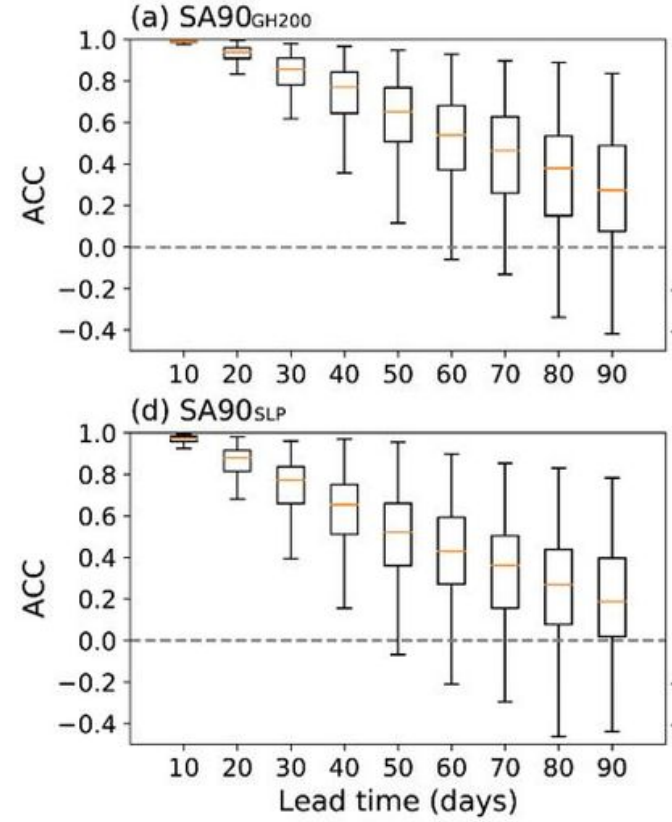

(b) SA90 $\mathrm{GH} 500$

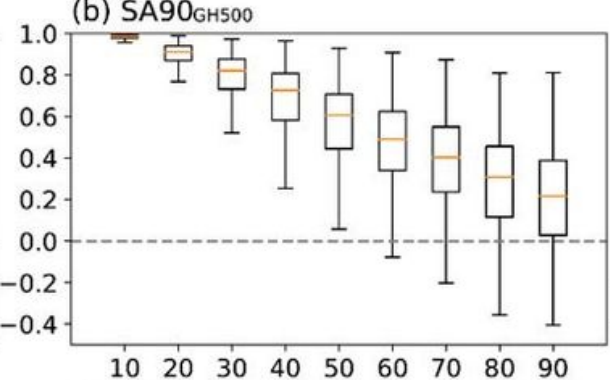

(e) SA90T2M

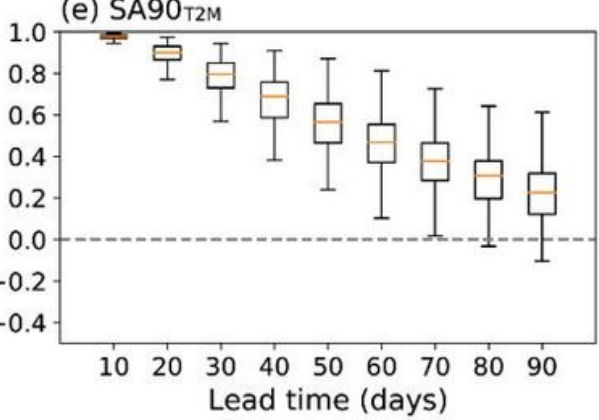

(c) $\mathrm{SA} 90_{\mathrm{GH}} 850$

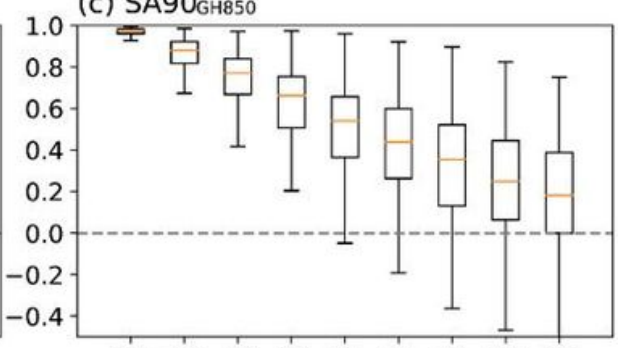

$\begin{array}{lllllllll}10 & 20 & 30 & 40 & 50 & 60 & 70 & 80 & 90\end{array}$ 
Figure 9

Boxplots of ACC for all atmospheric variables $\left(30^{\circ}-180^{\circ} \mathrm{E}, 10^{\circ} \mathrm{S}-90^{\circ} \mathrm{N}\right)$ with increasing lead times. The top to bottom five lines of a box plot represent the minimum, first quartile, median, third quartile, and maximum values of data, respectively
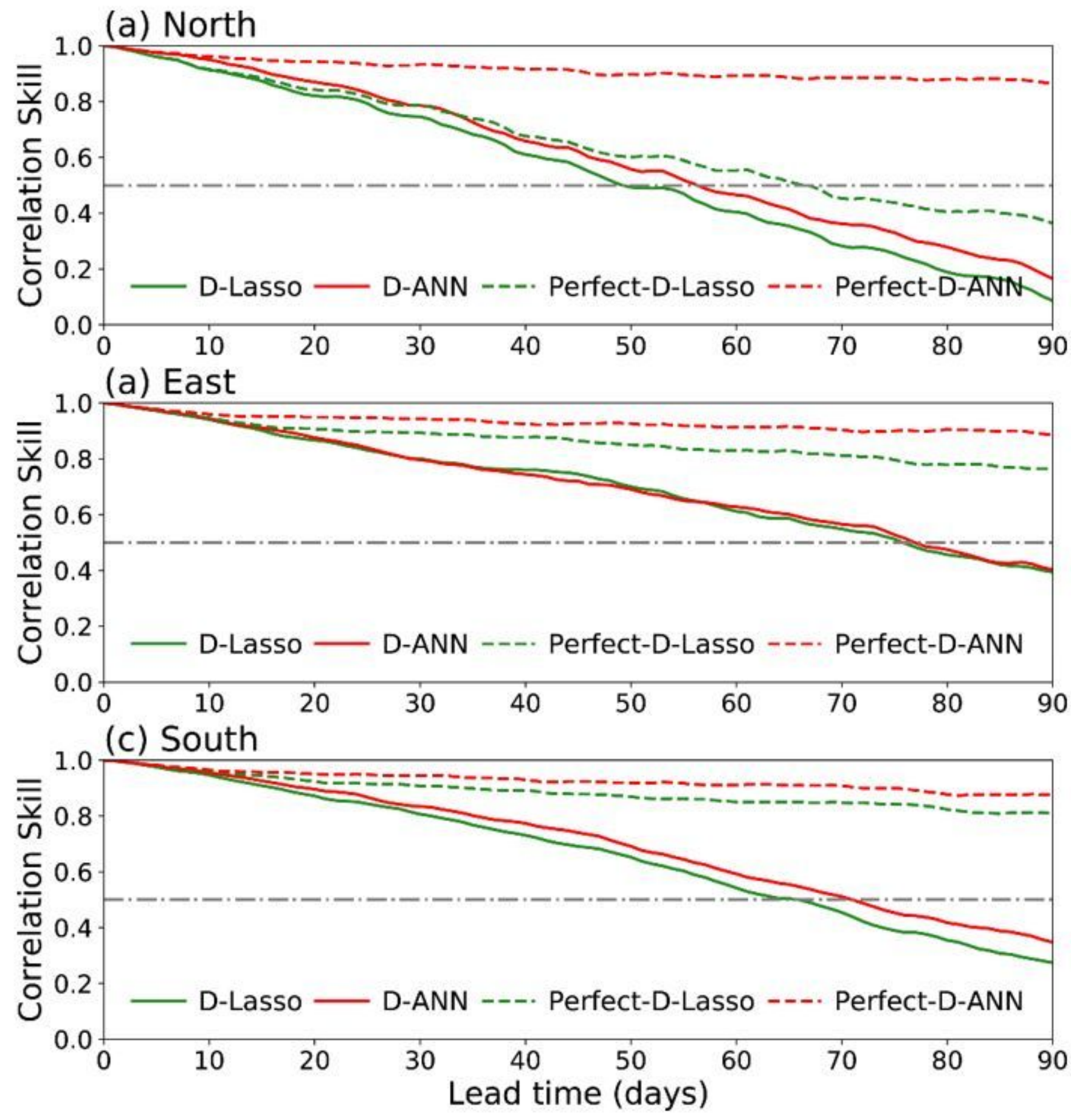

Figure 10

Correlation skills of four models predicting the SPI3 with different lead times in the different study regions. The solid green curves represent D-Lasso model predictions; the solid red curves represent D-ANN model predictions; the dashed green curves represent Perfect-D-Lasso model predictions; and the dashed 
red curves represent the Perfect-D-ANN model predictions. The dashed grey lines indicate a correlation of 0.5

\section{Supplementary Files}

This is a list of supplementary files associated with this preprint. Click to download.

- SupplementaryMaterial.docx 